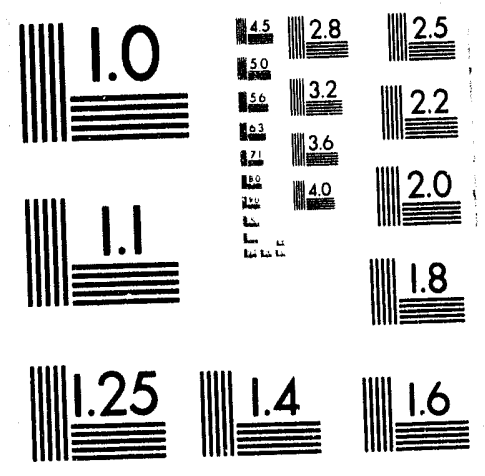




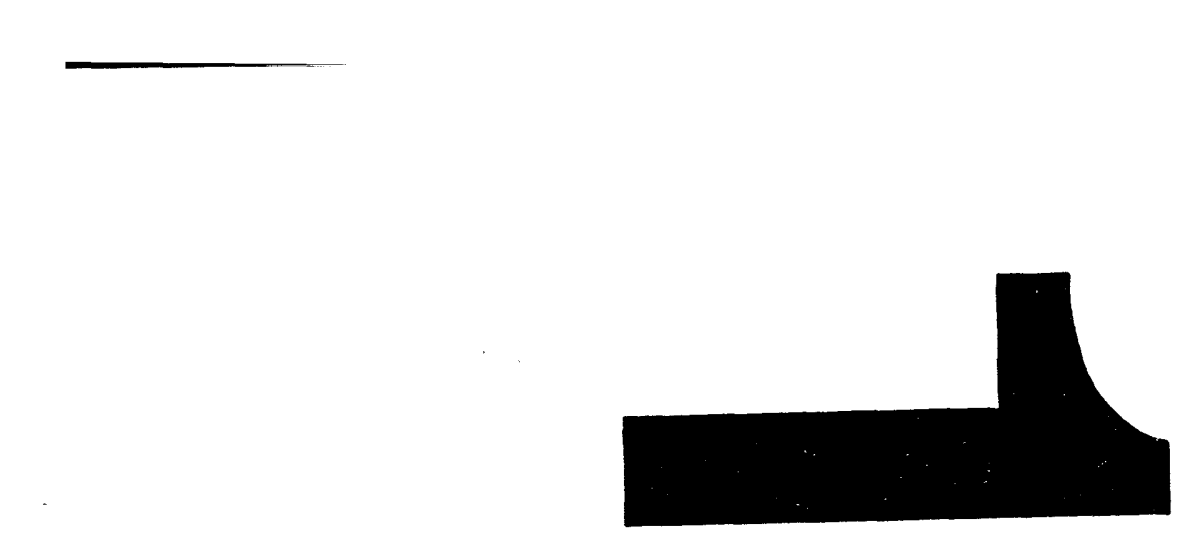


Ultrasonic Determination of the Elastic Moduli and their Pressure Dependences in Very Dense $\mathrm{YBa}_{2} \mathrm{Cu}_{3} \mathrm{O}_{7-\mathrm{x}^{*}}$

M. Cankurtaran, G. A. Saunders

University of Bath, Bath BA2 7AY, U.K.

K. C. Goretta and R. B. Poeppel

Materials and Components Technology Division

Argonne National Laboratory, Argonne, IL 60439, U.S.A.

\section{December 1991}

The submitted manuscript has been authored by
a contractor of the U.S. Government under
contract No. W-31-109-ENG-38. Accordingly, the
U.S. Government retains a nonexcluslve, royalty-
Iree llcense to publish or reproduce the published
lorm of this contribution, or allow others to do 20.
lor U.S. Government purposes.

.

fing 21 is

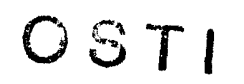

\title{
DISCLAIMER
}

\begin{abstract}
This report was prepared as an account of work sponsored by an agency of the United States Government. Neither the United States Government nor any agency thereof, nor any of their employees, makes any warranty, express or implied, or assumes any legal liability or responsibility for the accuracy, completeness, or usefulness of any information, apparatus, product, or process disclosed, or represents that its use would not infringe privately owned rights. Reference herein to any specific commercial product, process, or service by trade name, trademark, manufacturer, or otherwise does not necessarily constitute or imply its endorsement, recommendation, or favoring by the United States Government or any agency thereof. The views and opinions of authors expressed herein do not necessarily state or reflect those of the United States Government or any agency thereof.
\end{abstract}

*Work supported by the U.S. Department of Energy (DOE), Conservation and Renewable Energy, as part of a DOE program to develop electric power technology (KCG, RBP), under Contract W-31-109-Eng-38; by North Atlantic Treaty Organization Grant CRG 891033, and by grants from the Science and Engineering Research Council, TUBITAK, the Royal Society, and the British Council of Ankara (MC, GAS).

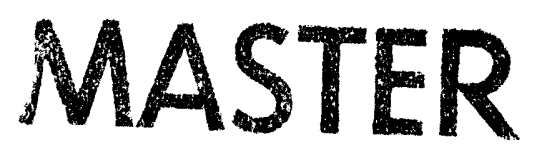


- ULTRASONIC DETERMINATION OF THE ELASTIC MODULI AND THEIR PRESSURE DEPENDENCES IN VERY DENSE $\mathrm{YBa}_{2} \mathrm{Cu}_{3} \mathrm{O}_{7 . x}$

M. Cankurtaran* and G.A. Saunders,

School of Physics, University of Bath, Claverton Down, Bath BA2 7AY, U.K.

K.C. Goretta and R.B. Poeppel

Materials and Components Technology Division, Argonne National Laboratory, Argonne, IL60439, USA.

*Permanent address: Hacettepe University, Department of Physics, Beytepe, 06532 Ankara, Turkey. 


\section{Abstract}

The effects of hydrostatic pressure and temperature have been measured on the velocities of longitudinal and shear ultrasonic waves propagated in a very dense ( $96 \%$ of theoretical density) ceramic specimen of $\mathrm{YBa}_{2} \mathrm{Cu}_{3} \mathrm{O}_{7-x}$. In $\mathrm{YBa}_{2} \mathrm{Cu}_{3} \mathrm{O}_{7-\mathrm{x}}$ ceramics with such a high density the effects of porosity on the elastic properties should be much reduced. Nevertheless the bulk modulus of this dense material has the same small magnitude ( $55 \mathrm{GPa})$ as that measured ultrasonically in much less dense $\mathrm{YBa}_{2} \mathrm{Cu}_{3} \mathrm{O}_{7 \cdot x}$ ceramics. The temperature dependences of the velocities of longitudinal and shear ultrasonic waves, which have been measured between $10 \mathrm{~K}$ and $300 \mathrm{~K}$, show the step-like increase at $200 \mathrm{~K}$ on cooling and a similar decrease at $225 \mathrm{~K}$ during warming with hysteresis in the range $190 \mathrm{~K}$ to $235 \mathrm{~K}$ that has previously observed in less dense ceramics and tentatively attributed to a phase transformation. The pressure dependences of both mode velocities for dense $\mathrm{YBa}_{2} \mathrm{Cu}_{3} \mathrm{O}_{7-x}$ ceramic show a pronounced change of slope at a pressure $P_{c}$. For pressures below and above $P_{c}$ the pressure dependence of ultrasonic velocity is essentially linear. Above the knee, the enormous pressure dependences of the longitudinal mode velocity and hence of the bulk modulus persist. The temperature dependences of pressure derivatives of elastic stiffnesses and bulk modulus have been measured between $250 \mathrm{~K}$ and $295 \mathrm{~K}$. The pressure $P_{c}$ at which the kink occurs decreases almost linearly with decreasing temperature and extrapolates to atmospheric pressure at about $220 \mathrm{~K}$. This is within the temperature range where the steep changes in temperature dependence of the ultrasonic velocities occur suggesting that the anomalous elastic behaviour under pressure at $P_{c}$ correlates with that observed at about 200-235K at atmospheric pressure. The mean long wavelength acoustic mode Grüneisen parameter $\gamma^{l}$ has the large value of 11 implying that the vibrational anharmonicity of the long wavelength acoustic modes is considerable. 


\section{Introduction}

Knowledge of the elastic moduli and their dependences upon hydrostatic pressure for well characterised low porosity ceramics and monocrystalline high $T_{c}$ superconducting materials is still insufficient to provide a firm foundation on which to base an understanding of their elastic and non-linear acoustic properties. One outstanding problem is that the bulk modulus $B_{o}$ at atmospheric pressure obtained from ultrasonic measurements on ceramic samples of $\mathrm{YBa}_{2} \mathrm{Cu}_{3} \mathrm{O}_{7-\mathrm{x}}[1-3]$ (and other related cuprates, including $\mathrm{GdBa}_{2} \mathrm{Cu}_{3} \mathrm{O}_{7 \cdot \mathrm{x}}$ in both its orthorhombic and tetragonal forms [4,5], $\mathrm{Bi}_{2} \mathrm{Sr}_{2} \mathrm{Ca}_{\mathrm{n}-1} \mathrm{Cu}_{\mathrm{n}} \mathrm{O}_{4+2 \mathrm{a}}$ (with $\mathrm{n}=2$ and 3) [6] and $\mathrm{La}_{1.8} \mathrm{Sr}_{0.2} \mathrm{CuO}_{4}$ [3]) is much smaller than that $B^{T}(P)$ determined [7-12] at very high pressures from $\mathrm{x}$-ray measurements of lattice parameters in a diamond cell. This difference has been ascribed [1-6] to the large magnitude of $(\partial B / \partial P)_{P=O}$ determined from the effects of hydrostatic pressure on ultrasonic wave velocity. A recent reanalysis [13] of the high pressure $x$-ray [7-12] and neutron [14-16] diffraction data has led to a substantial reduction of $B^{T}(P)$ and a large increase in the value of its pressure derivative $(\partial B / \partial P)$ : both trending towards the ultrasonic values and confirming the earlier observation $[1,2]$ of the highly pressure dependent nature of the bulk modulus at moderate pressures. Hence the question as to whether the true bulk modulus of $\mathrm{YBa}_{2} \mathrm{Cu}_{3} \mathrm{O}_{7-\mathrm{x}}$ is the smaller ultrasonic value at atmospheric pressure or the much larger one obtained from high pressure lattice parameter data has to some extent been resolved in favour of the former. Nevertheless, in view of the fundamental and technological importance of having a precise knowledge of the elastic moduli and their pressure derivatives, critical appraisal of the measurement techniques and their output remains necessary until the experimental problems are satisfactorily resolved: more work on the elastic behaviour of the high $\mathrm{T}_{\mathrm{c}}$ superconductors is necessary before the results of one particular method can be given preference.

As we have emphasised in earlier work, it is not certain whether the strong pressure dependence of ultrasonic wave velocity, and hence of bulk modulus, is a consequence of 
microstructure or if it is an intrinsic property of these cuprates. How much does specimen - microstructure, particularly porosity, microfracture, twinning and grain size, of ceramic $\mathrm{YBa}_{2} \mathrm{Cu}_{3} \mathrm{O}_{7-\mathrm{x}}$ influence its elastic and mechanical properties? The effects of porosity on the elastic properties can be taken into account by use of wave scattering theory in a porous medium [1]; it has been shown that porosity decreases the elastic moduli. The presence of cracks can also reduce the stiffness of a material [17-20]. To study the problem further, it is useful to examine material in which the porosity is made as small as possible. Therefore measurements of temperature and hydrostatic pressure dependences of ultrasonic wave velocities have been made in a very dense ( $96 \%$ of theoretical density) $\mathrm{YBa}_{2} \mathrm{Cu}_{3} \mathrm{O}_{7 \cdot \mathrm{x}}$ ceramic prepared by a variation of the usual solid state reaction technique [21]. The aim has been to determine the elastic moduli and their temperature and pressure dependences in $\mathrm{YBa}_{2} \mathrm{Cu}_{3} \mathrm{O}_{7 \cdot \mathrm{x}}$ ceramic with minimized effects of porosity.

\section{Experimental procedures}

Phase-pure orthorhornbic $\mathrm{YBa}_{2} \mathrm{Cu}_{3} \mathrm{O}_{7 \cdot \mathrm{x}}$ powder was synthesised by a solid state reaction procedure during which the ratio of $\mathrm{O}_{2}$ to $\mathrm{CO}_{2}$ was kept higher than 50 [21]. This powder was cold pressed into pellets which were sintered in $\mathrm{O}_{2}$ at $980^{\circ} \mathrm{C}$ for three hours. The heating and cooling rates were $3^{\circ} \mathrm{C} / \mathrm{min}$, but to obtain high density material no post-sinter oxygenation annealing was employed so that the specimens contain some tetragonal phase at room temperature. The critical current density of the product was about $1.0 \times 10^{3} \mathrm{Acm}^{-2}$ at $77 \mathrm{~K}$ in the absence of a magnetic field [21], which is about twice that of material made from powders produced by more conventional processes. The sample density, determined by Archimedes' principle using acetone as the floatation liquid, was $6070 \mathrm{kgm}^{-3}$ which is $95.8 \%$ of the X-ray density, so its mean porosity $n$ is 0.042 . This material is substantially denser than any $\mathrm{YBa}_{2} \mathrm{Cu}_{3} \mathrm{O}_{7 \cdot \mathrm{x}}$ ceramic whose ultrasonic velocities have been determined as a function of temperature and pressure; the densest sample previously examined had a porosity of 0.056 [1,2]. Microstructural
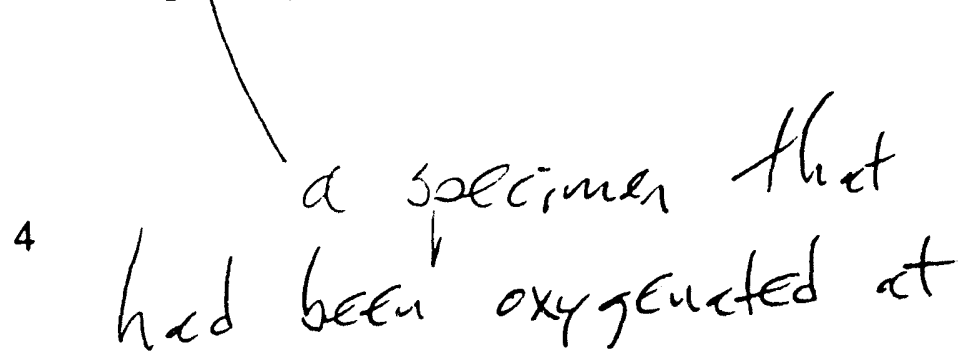
examination revealed the material to have a fairly uniform distribution of small grains of size less than about $30 \mu \mathrm{m}$.

Pellets were polished lightly to give flat and parallel faces to about $10^{-4} \mathrm{rad}$. Ultrasonic pulses were propagated along the direction of pressing and were generated and detected by $\mathrm{X}$ or Y-cut (for longitudinal and shear waves respectively) quartz transducers bonded to the specimen using Nonaq in the low temperature experiments. Measurements of the temperature dependence of ultrasonic wave velocity were made in a closed cycle refrigerator in the temperature range $10 \mathrm{~K}$ to $300 \mathrm{~K}$. The temperature was changed at a rate about $0.5 \mathrm{~K} / \mathrm{min}$ during both cooling and warming cycles. Dow resin was used as the bonding material for the high pressure measurements which were made in the range between $250 \mathrm{~K}$ and $295 \mathrm{~K}$. Hydrostatic pressures up to $0.15 \mathrm{GPa}$ were applied to the samples using a piston-and-cylinder apparatus with silicone oil as the pressure transmitting medium. Pressure was measured using a pre-calibrated manganin resistance gauge. To determine the effects of temperature and pressure on the ultrasonic wave transit time, a pulse-echo overlap system [22] capable of measuring changes to 1 part in $10^{5}$ in ultrasonic transit time in these ceramic specimens was used. A transducer correction [23] was applied to the measured transit time and hence to the ultrasonic wave velocities. Pressure induced changes in the sample dimensions were taken into account by using the "natural velocity $(W)$ " technique [24].

\section{Ultrasonic wave velocities and elastic stiffnesses}

The velocities of longitudinal $V_{L}$ and shear $V_{S}$ ultrasonic waves propagated in dense $\mathrm{YBa}_{2} \mathrm{Cu}_{3} \mathrm{O}_{7-\mathrm{x}}$ at $295 \mathrm{~K}$ are given in table 1 . This small-grained polycrystalline ceramic can be treated as an isotropic material having two independent elastic stiffness moduli $C_{L}\left(=\rho V_{L}^{2}\right)$ and $\mu\left(=\rho V_{S}^{2}\right)$. These elastic stiffness moduli, the adiabatic bulk modulus $B_{o}$, the Young's modulus $E$, the Poisson's ratio $\sigma$ and the acoustic Debye temperature $\theta_{D}^{e l}$ have been determined using the velocity data and specimen density $\rho$ (table 1 ). To assess the effects of porosity on the elastic properties, 
corrections for the influence of specimen porosity have been made for the room temperature

- data using the results of wave scattering theory [1] in a porous medium, the validity of which has been discussed elsewhere [3]. Comparison between the results obtained on the sample with those determined for the non-porous matrix (table 1) shows that the effect of a porosity is to reduce the ultrasonic wave velocity (by about $2 \%$ ) and hence the elastic stiffness moduli, including the bulk modulus.

The ultrasonic wave velocities in this dense, comparatively small grained $\mathrm{YBa}_{2} \mathrm{Cu}_{3} \mathrm{O}_{7-\mathrm{x}}$ ceramic sample at room temperature fall within the rarige of values measured on both coarse-grained and fine-grained ceramic materials [1,2] and a very large-grained halide flux-grown specimen [3] (table 2). A theoretical calculation [25] of the elastic stiffness moduli predicts similar sound wave velocities for polycrystalline $\mathrm{YBa}_{2} \mathrm{Cu}_{3} \mathrm{O}_{7 \times \mathrm{x}}$ (table 2). For single-crystal $\mathrm{YBa}_{2} \mathrm{Cu}_{3} \mathrm{O}_{7-x}$ a comparable value for an average longitudinal wave velocity of $4460 \mathrm{~ms}^{-1}$ was obtained [3] from published data [26]; the single-crystal ultrasonic wave velocity measurements of Saint-Paul et al [27] are in accord with this. These observations evidence that the ultrasonic technique measures correct sound wave velocities for the ceramics.

A further test of the validity of the ultrasonic velocity data is provided by a comparison of the elastic Debye temperature $\left(\theta_{D}^{e l}\right)$ obtained from ultrasonic wave velocities for the non-porous matrix with that $\left(\theta_{D}\right)$ determined from specific heat data (which should be independent of porosity). At low temperatures $\theta_{D}^{a l}$ should be equal to $\theta_{D}$. For the fine-grained [3] and the dense $\mathrm{YBa}_{2} \mathrm{Cu}_{3} \mathrm{O}_{7-\mathrm{x}}$ the values obtained for $\theta_{D}^{e l}$ using ultrasonic velocities measured at $10 \mathrm{~K}$ are $435 \mathrm{~K}$ and $450 \mathrm{~K}$ respectively. These are in good agreement with the limiting $\theta_{D}$ of $432 \mathrm{~K}$ obtained from specific-heat measurements [28]. Therefore, the velocities measured ultrasonically, and hence the bulk modulus, are compatible with the low temperature specific heat.

Microcracks are produced in $\mathrm{YBa}_{2} \mathrm{Cu}_{3} \mathrm{O}_{7-\mathrm{x}}$ as a result of anisotropic thermal contraction on cooling the ceramic and also of oxygen uptake; microcracking is more pronounced in material with larger grains [29-32]. However grain size does not play a significant role in determining 
the ultrasonic wave velocities and the elastic stiffness moduli of ceramic $\mathrm{YBa}_{2} \mathrm{Cu}_{3} \mathrm{O}_{7 \cdot \mathrm{x}}$ samples of similar density (table 2). Microcracking does not produce an anomalously low bulk modulus.

The effects of temperature during both cooling and warming cycles on the longitudinal and shear ultrasonic wave velocities are shown in figures 1 and 2 . Below about $170 \mathrm{~K}$ the ultrasonic velocities show no thermal hysteresis between cooling and warming and can be fitted by the conventional model of vibrational anharmonicity [33]. The most striking feature is that both mode velocities show a steep increase at $\sim 200 \mathrm{~K}$ (during cooling) and a steep decrease at $\sim 225 \mathrm{~K}$ (during warming), and a hysteresis loop between about $190 \mathrm{~K}$ and $235 \mathrm{~K}$. The change in the shear modulus at about $200 \mathrm{~K}$ is 1.7 times larger than that of the bulk modulus in agreement with a suggestion [34] that the effect involved may be driven by a shear instability. Similar features in the ultrasonic velocities have been observed in the same temperature region in less dense $\mathrm{YBa}_{2} \mathrm{Cu}_{3} \mathrm{O}_{7-x}$ [34-36], orthorhombic $\mathrm{GdBa}_{2} \mathrm{Cu}_{3} \mathrm{O}_{7 \cdot \times}$ [37,38], and bismuth cuprates $\mathrm{Bi}(\mathrm{Pb}) 2223[39,40]$ and $\mathrm{Bi} 2212[40]$. Anomalous changes in the slope of the temperature dependence of Young's modulus of single-crystal $\mathrm{YBa}_{2} \mathrm{Cu}_{3} \mathrm{O}_{7 \cdot \mathrm{x}}$ have been observed [41] in the vicinity of $200 \mathrm{~K}$ (cooling) and $240 \mathrm{~K}$ (warming) using a low frequency vibrating-reed technique: this unusual elastic behaviour is frequency independent and not a property of ceramics only. Pronounced hysteresis has also been found [26] in the temperature dependences of the $\mathrm{C}_{33}$ and $\mathrm{C}_{44}$ modes in single-crystal $\mathrm{YBa}_{2} \mathrm{Cu}_{3} \mathrm{O}_{7 \cdot \mathrm{x}}$ showing that the hysteresis effects are not confined to ceramic samples. The elastic anomaly in the range between $200 \mathrm{~K}$ and $240 \mathrm{~K}$ has been attributed [34] to an order-disorder phase transition involving the oxygen ions in the copper-oxygen planes. It has been suggested [34] that the development of the lower temperature phase could be related to the high $\mathrm{Tc}$ superconductivity in $\mathrm{YBa}_{2} \mathrm{Cu}_{3} \mathrm{O}_{7-\mathbf{x}}$.

\section{Hydrostatic pressure dependences of ultrasonic wave velocities and elastic stiffnesses} The effects of hydrostatic pressure on longitudinal and shear ultrasonic wave velocities for dense $\mathrm{YBa}_{2} \mathrm{Cu}_{3} \mathrm{O}_{7-x}$, at selected temperatures, are shown in figures 3 and 4 respectively. The 
measurements are reproducible and show no hysteresis effects under pressure cycling. The longitudinal mode velocity is much more pressure dependent than that of the shear mode. The pressure dependences of both mode velocities show a pronounced change of slope at a pressure $P_{c}$ (marked by an arrow). For pressures below and above $P_{c}$ the pressure dependence of ultrasonic velocity is reasonably linear. Above the knee, the pressure derivative of the velocity becomes substantially smaller. One possible explanation of this observation might be that the first effect of the application of pressure is to close any microcracks, reduce the pore volume somewhat and increase the adhesion between the grains. However, this interpretation is challenged by the absence of hysteresis. Furthermore there is a strong temperature dependence of the hydrostatic pressure derivatives of elastic stiffnesses (see below figures 9 and 10) which is not consistent with there being a substantial contribution from microcrack closure to the anomalously large pressure dependences of ultrasonic wave velocities and hence of the elastic stiffnesses and bulk modulus.

The pressure $P_{c}$ is temperature dependent and decreases almost linearly with decreasing temperature (figure 5). The straight line extrapolates to atmospheric pressure at about $220 \mathrm{~K}$. Intriguingly this is within the temperature range where the steep changes in temperature dependence of the ultrasonic velocities occur (figures 1 and 2), suggesting that the anomalous elastic behaviour with temperature at about $200-235 \mathrm{~K}$ and that under pressure at $P_{c}$ might be related. Thus another possible explanation of the knee observed in velocity versus pressure data (figures 3 and 4 ) is that at $P_{c}$ there is a transition to a new phase having smaller pressure dependence of ultrasonic wave velocities. The anomalous elastic effect in the temperature dependence observed at $200 \mathrm{~K}-235 \mathrm{~K}$ would be shifted up to the room temperature by application of a pressure of about $0.06 \mathrm{GPa}$.

The pressure dependences of the longitudinal $\left(C_{L}\right)$ and shear $(\mu)$ moduli and the bulk modulus $(B)$ obtained directly from the experimental data collected at $295 \mathrm{~K}$ and of those corresponding to the non-porous matrix are plotted in figures 6 to 8 . The curves for the 
non-porous matrix are shifted upwards with respect to the experimental results: for this particularly dense $\mathrm{YBa}_{2} \mathrm{Cu}_{3} \mathrm{O}_{7-\mathrm{x}}$ ceramic the effect of the porosity is to reduce the elastic stiffness moduli and the bulk modulus, but the presence of pores does not substantially alter their pressure dependences. It should be noted that the data presented in figures 6 to 8 cannot be used directly to calculate the pressure derivatives of elastic moduli, since they do not include the correction required to account for pressure induced changes in sample dimensions.

To obtain the hydrostatic pressure derivatives $\left(\partial C_{L} / \partial P\right)_{P=0},(\partial \mu / \partial P)_{P=0}$ and $(\partial B / \partial P)_{P=0}$ in the limit as pressure tends towards zero and those $\left(\partial C_{L} / \partial P\right)_{P},(\partial \mu / \partial)_{P}$ and $(\partial B / \partial P)_{P}$ for pressures above the knee, the experimental results for the effects of hydrostatic pressure on the pulse-echo overlap frequency have first been converted to the relative change in natural velocity $d\left(\Delta W / W_{0}\right) / d P$ in order to account for the pressure induced changes in sample dimensions. The results for the pressure derivatives of the elastic stiffnesses and the bulk modulus are given in table 3, which also includes the ultrasonic velocities and the elastic moduli. The temperature dependences of these pressure derivatives in the range between $250 \mathrm{~K}$ and $295 \mathrm{~K}$ are presented in figure 9 (in the limit as pressure tends towards zero) and figure 10 (for pressures above the knee). All the pressure derivatives are anomalously large. Above the knee there is a pronounced decrease in their values (table 3 ) emphasising the highly pressure dependent nature of the elastic stiffnesses, the bulk modulus and their pressure derivatives in $\mathrm{YBa}_{2} \mathrm{Cu}_{3} \mathrm{O}_{7 \cdot \mathrm{x}}$.

The presence of irregularly shaped pores, grain boundaries, microcracks and intergranular defects can have substantial effects on the elastic stiffnesses and their pressure dependences. However, microstructural effects are not the major source of the large values of $\left(\partial C_{L} / \partial P\right)$ and $(\partial B / \partial P)$ for $\mathrm{YBa}_{2} \mathrm{Cu}_{3} \mathrm{O}_{7-\mathrm{x}}$ : similar values (table 2 ) have been measured for samples of quite different density and wide range of grain size which have different patterns of microstructural defects including the amount and extent of microfracture. Thus a large value of $\left(\partial C_{L} / \partial P\right)$ and hence $(\partial B / \partial P)$ seems to be an intrinsic property of $\mathrm{YBa}_{2} \mathrm{Cu}_{3} \mathrm{O}_{7 \cdot x}$, as suggested previously [1-3]. Further support for this proposition comes from the measurements of the temperature 
dependences of the pressure derivatives of elastic stiffnesses and bulk modulus (table 3 , figures 9 and 10). Although the elastic stiffnesses and the bulk modulus increase slightly as the temperature is decreased from $295 \mathrm{~K}$ to $250 \mathrm{~K}$, the hydrostatic pressure derivatives $\left(\partial C_{L} / \partial P\right)_{P=0}$ and $(\partial B / \partial P)_{P=0}$ increase rapidly while $(\partial \mu / \partial P)_{P=0}$ decreases (figure 9). These findings are not consistent with the possibility that the large $(\partial B / \partial P)_{P=0}$ is due to microcrack closure. The density and dimensions of microcracks and the force required to close them would not be expected to change much in this relatively narrow temperature range.

The temperature dependence of $(\partial \mu / \partial P)_{P=0}$ (figure $\left.9(c)\right)$ is opposite to that of $(\partial \mu \partial P)_{P}$ (figure 10(c)): the former decreases while the latter increases as the temperature is decreased from $295 \mathrm{~K}$ to $250 \mathrm{~K}$. It is interesting to recall the suggestion [34] that the anomalous elastic behaviour in the temperature range $200 \mathrm{~K}$ to $235 \mathrm{~K}$ (figures 1 and 2) could be driven by shear instability; the differences between the temperature dependences of the pressure derivatives of the shear modulus below and above the knee (figures $9(\mathrm{c})$ and $10(\mathrm{c})$ ) are consistent with this.

\section{The bulk modulus of $\mathrm{YBa}_{2} \mathrm{Cu}_{3} \mathrm{O}_{7-x}$ and its hydrostatic pressure derivative}

The discrepancy found for $\mathrm{YBa}_{2} \mathrm{Cu}_{3} \mathrm{O}_{7 \times \mathrm{x}}$ between $B_{0}$ and $B^{T}(P)$ can be resolved by taking the large contribution from $P(\partial B / \partial P)_{P=o}$ to the bulk modulus $B^{T}(P)$ at high pressure into account $[1,3]$. Although there is reasonable agreement between $B^{T}(P)$ and the estimated value of $B(P)=B_{0}$ $+P(\partial B / \partial P)_{P=0}$ at pressure $P$, using the experimental values of $B_{o}$ and $(\partial B / \partial P)_{P=0}$, uncertainty remains as to the source of the huge value of $(\partial B / \partial P)_{P}=0$ measured ultrasonically. For orthorhombic $\mathrm{YBa}_{2} \mathrm{Cu}_{3} \mathrm{O}_{7-\mathrm{x}}$ (with $\mathrm{x}=0.1$ ) a theoretical calculation [42] of $\partial B / \partial P$ has given a value of 5.0 and estimations $[10,12]$ from high pressure $x$-ray lattice parameter measurements lead to values of 2.9 and 5.5 .

At the high pressures $(>1 \mathrm{GPa})$ involved in the diamond cell experiments the unit cell volume is substantially reduced: the bulk modulus $B^{T}(P)$ data reported in references $[7,10,12]$ correspond to values for the material under high compression, which enhances the bulk modulus 
and reduces $\partial B / \partial P$. Recently, Fietz et al. [13] have reviewed the situation regarding the elastic properties of high $T_{c}$ superconductors derived from high pressure experiments. They have compiled the available lattice parameter data from $x$-ray [7-12] and neutron diffraction [14-16] investigations under pressure and reanalysed them taking the non-linear pressure dependence of lattice parameters into account. They now conclude that the compressibility (and therefore its inverse the bulk modulus) of high $T_{c}$ superconductors is extremely pressure dependent at small pressures. The results of their reassessment are: (i) a relatively small bulk modulus, although it is somewhat larger than that derived from ultrasound experiments, (ii) very large values of $\partial B / \partial P: 39$ for $\mathrm{YBa}_{2} \mathrm{Cu}_{4} \mathrm{O}_{8}, 16$ for $\mathrm{La}_{1.8} \mathrm{Sr}_{0.2} \mathrm{CuO}_{4}, 64$ for $\left(\mathrm{Nd}_{1-x} \mathrm{Sr}_{\mathrm{x}}\right)\left(\mathrm{Nd}_{1-y} \mathrm{Ce}_{y}\right) \mathrm{CuO}_{4}, 28$ for $\mathrm{YBa}_{2} \mathrm{Cu}_{3} \mathrm{O}_{6.93}$ and 47 for $\mathrm{YBa}_{2} \mathrm{Cu}_{3} \mathrm{O}_{6.6}$, which are now in the ranges of values obtained from Lltrasonic wave velocity measurement under pressure. Since the bulk modulus of high $\mathrm{T}_{c}$ superconductors is very pressure dependent, care must be taken when comparing the bulk modulus and $\partial B / \partial P$ obtained from different techniques performed in different pressure regions: the $x$-ray diffraction measurements above $1 \mathrm{GPa}$, neutron diffraction investigations jetween about $0.1 \mathrm{GPa}$ and $0.6 \mathrm{GPa}$ (in steps of about $0.1 \mathrm{GPa}$ ), the ultrasonic wave velocity measurements in the pressure range up to $0.15 \mathrm{GPa}$. Although the ultrasonic technique is the most sensitive way for measurement of the pressure dependence of elastic stiffnesses, it can only be used at comparatively low pressures and may be influenced by specimen microstructure. While the bulk modulus can be derived at much higher pressures using neutron and $\mathrm{x}$-ray diffraction, these methods are restricted by sensitivity and the difficulty of taking extensive data and hence of fitting the volume compressibility versus pressure data to the particular equation of state chosen [43]. As a result there are marked differences between bulk modulus values obtained from the $x$-ray method [13]. At this stage placing too much trust in the superiority of one particular method is unhelpful. 


\section{Acoustic mode vibrational anharmonicity of $\mathrm{YBa}_{2} \mathrm{Cu}_{3} \mathrm{O}_{7-\mathrm{x}}$}

The measurements of the pressure derivatives of the elastic constants enable an assessment of the magnitudes of the anharmonicities associated with the long wavelength acoustic modes. The experimental observation that the ultrasonic wave velocities are strongly pressure dependent results in a very large mean long-wavelength acoustic mode Grüneisen parameter $\boldsymbol{\gamma}^{l}$ compared with the thermal Grüneisen parameter $\gamma^{h}[2,44]$. The mean long wavelength acoustic mode Grüneisen parameter $\gamma^{\prime}(=11)$ of this very dense $\mathrm{YBa}_{2} \mathrm{Cu}_{3} \mathrm{O}_{7-x}$, obtained using the data above $P_{c}$, is as large as that of the less dense material [2,3]. There is now a considerable body of evidence that microstructural defects are not the prime source of the large pressure dependence of ultrasonic wave velocities and hence of the large $\gamma^{l}$. It has been shown [45] that the Grüneisen parameters of isotropic solids can decrease with increasing microcrack density.

The difference between $\gamma^{l}$ and $\gamma^{\text {h }}$ found for $\mathrm{YBa}_{2} \mathrm{Cu}_{3} \mathrm{O}_{7 \times x}$ remains unexplained. The ultrasonic data under pressure indicate a much stronger vibrational anharmonicity of the long wavelength acoustic phonons than that suggested by the mean anharmonicity summed over the entire phonon population. Confirmatory evidence of large vibrational anharmonicity of phonons in $\mathrm{YBa}_{2} \mathrm{Cu}_{3} \mathrm{O}_{7 \cdot \mathrm{x}}$ has come from other experiments: ultrasonic measurement of the non-linearity of the longitudinal waves using second harmonic generation [46]; ultrasonic measurements at low temperatures made [27] on single crystal $\mathrm{YBa}_{2} \mathrm{Cu}_{3} \mathrm{O}_{7-x}$; high temperature Raman spectra [47]; $x$-ray absorption fine-structure (EXAFS) data [48]. Thus it appears that in $\mathrm{YBa}_{2} \mathrm{Cu}_{3} \mathrm{O}_{7-x}$ the vibrational anharmonicity of certain optic and long wavelength acoustic phonons is large. Certainly it can be anticipated that the pronounced phonon anharmonicity must have a substantial influence on the individual mode Grüneisen parameters. Large phonon anharmonicities could be of considerable theoretical importance, as Müller [49] has recently stressed in an evaluation of the remarks of many contributors to the field that in the context of BCS theory anharmonic motion of ions could generate a large electron-phonon coupling constant $\lambda$ possibly for $\mathrm{YBa}_{2} \mathrm{Cu}_{3} \mathrm{O}_{7 \cdot \mathrm{x}}$ via anharmonic coupling of pyramidal apex oxygen $\mathrm{O}(1)$ motion along the $\mathrm{c}$-axis 
direction (see also reference [50]). In addition to being responsible for a large anharmonicity of the corresponding optic modes, such motion would affect the acoustic modes through optic phonon-acoustic phonon interactions.

\section{Conclusions}

(i) For dense $\mathrm{YBa}_{2} \mathrm{Cu}_{3} \mathrm{O}_{7 \cdot x}$ ceramic the temperature dependences of both longitudinal and shear wave velocities show a steep increase at $200 \mathrm{~K}$ (during cooling) and a steep decrease at $225 \mathrm{~K}$ (during warming) and a well pronounced hysteresis loop in the temperature range between $190 \mathrm{~K}$ and $235 \mathrm{~K}$.

(ii) There is remarkable decrease in the slope of hydrostatic pressure dependences of both longitudinal and shear wave velocities above a pressure $P_{c}$ which decreases linearly with decreasing temperature from $295 \mathrm{~K}$ to $250 \mathrm{~K}$ and extrapolates to atmospheric pressure at about 220K. There is a correlation between the anomalous elastic behaviour under pressure about $P_{c}$ and that in the temperature range of $200-235 \mathrm{~K}$ which has been attributed to a phase transition.

(iii) The bulk modulus $(=55 \mathrm{GPa})$ of this particularly dense material at room temperature and atmospheric pressure has the same small magnitude as that measured ultrasonically in less dense $\mathrm{YBa}_{2} \mathrm{Cu}_{3} \mathrm{O}_{7-\mathrm{x}}$ ceramics.

(iv) The pressure derivative of bulk modulus $\partial B / \partial P$ is enormous. This feature is now compatible with that obtained [13] from a reassessment of lattice parameter data from neutron diffraction measurements in the pressure range up to $0.6 \mathrm{GPa}$. This reinforces the proposition [1] that a comparatively small bulk modulus and a large $\partial B / \partial P$ are probably intrinsic properties of $\mathrm{YBa}_{2} \mathrm{Cu}_{3} \mathrm{O}_{7 \cdot \mathrm{x}}$.

(v) The vibrational anharmonicity of the long wavelength acoustic phonons is large. 


\section{Acknowledgements}

We are grateful to the Science and Engineering Research Council (SERC) for financial support.

Dr.M. Cankurtaran and Professor G.A. Saunders acknowledge with gratitude North Atlantic Treaty Organization (NATO) Grant No.CRG 891033. Dr. K.C. Goretta and Dr. R.B. Poeppel would also like to acknowledge the support of the U.S.Department of Energy (DOE), Office of Conservation and Renewable Energy, as part of a DOE programme to develop electric power technology, under Contract W-31-109-Eng-38. Dr.M. Cankurtaran is grateful to TUBITAK (TBAG, Ankara), the Royal Society and the British Council (Ankara) for research grants. We would like to thank our colleagues W.A. Lambson, E.F. Lambson and Barry Chapman for technical assistance and last but by no means least Dr. D.P. Almond for many constructive discussions. 


\section{Figure captions}

Figure 1. The temperature dependence of the velocity of longitudinal $5 \mathrm{MHz}$ ultrasonic waves propagated in the dense $\mathrm{YBa}_{2} \mathrm{Cu}_{3} \mathrm{O}_{7-x}$ ceramic. The crosses refer to data obtained as the temperature was reduced and the squares as it was increased.

Figure 2. The temperature dependence of the velocity of shear $5 \mathrm{MHz}$ ultrasonic waves propagated in the dense $\mathrm{YBa}_{2} \mathrm{Cu}_{3} \mathrm{O}_{7-\mathrm{x}}$ ceramic. The crosses refer to data obtained as the temperature was reduced and the squares as it was increased.

Figure 3. The hydrostatic pressure dependences of the velocities of longitudinal $5 \mathrm{MHz}$ ultrasonic waves propagated in the dense $\mathrm{YBa}_{2} \mathrm{Cu}_{3} \mathrm{O}_{7-x}$ ceramic at selected temperatures: (a) $294.1 \mathrm{~K}$, (b) $273.1 \mathrm{~K}$, (c) $262.8 \mathrm{~K}$, (d) $253.1 \mathrm{~K}$. The crosses correspond to velocity measurements made with increasing pressure and the squares to data obtained as the pressure was decreased.

Figure 4. The hydrostatic pressure dependences of the velocities of shear $10 \mathrm{MHz}$ ultrasonic waves propagated the in the dense $\mathrm{YBa}_{2} \mathrm{Cu}_{3} \mathrm{O}_{7 \cdot \mathrm{x}}$ ceramic at selected temperatures: (a) $295.8 \mathrm{~K}$, (b) $283.1 \mathrm{~K}$, (c) $278.7 \mathrm{~K}$, (d) $253.1 \mathrm{~K}$. The crosses correspond to velocity measurements made with increasing pressure and the squares to data obtained as the pressure was decreased.

Figure 5. The temperature dependence of the pressure $P_{c}$ at which the anomalous elastic behaviour has been observed in the pressure dependence of the shear wave velocity (figure 4). The temperature dependence of $P_{c}$ extrapolates linearly to atmospheric pressure about $220 \mathrm{~K}$ which is within the range in which the step occurs in the temperature dependence of the velocity of longitudinal (figure 1) and shear (figure 2) ultrasonic waves. 
Figure 6. The hydrostatic pressure dependences at $295 \mathrm{~K}$ of the longitudinal stiffness modulus $C_{L}$ for the dense sample of $\mathrm{YBa}_{2} \mathrm{Cu}_{3} \mathrm{O}_{7-\times}$ (lower curve) and the non-porous matrix (upper curve). Correction for porosity shifts the curve up but has little effect on the pressure gradients.

Figure 7. The hydrostatic pressure dependences at $295 \mathrm{~K}$ of the shear stiffness modulus $\mu$ for the dense sample of $\mathrm{YBa}_{2} \mathrm{Cu}_{3} \mathrm{O}_{7 \cdot x}$ (lower curve) and the non-porous matrix (upper curve). Correction for porosity shifts the curve up but has little effect on the pressure gradients.

Figure 8. The hydrostatic pressure dependences at $295 \mathrm{~K}$ of the bulk modulus $B$ for the dense sample of $\mathrm{YBa}_{2} \mathrm{Cu}_{3} \mathrm{O}_{7-\mathrm{x}}$ (lower curve) and the non-porous matrix (upper curve). Correction for porosity shifts the curve up but has little effect on the pressure gradients.

Figure 9. The temperature dependences of the hydrostatic pressure derivatives of the elastic stiffnesses and the bulk modulus in the low pressure limit (as the pressure tends towards zero) for the dense $\mathrm{YBa}_{2} \mathrm{Cu}_{3} \mathrm{O}_{7 \cdot-x}$ ceramic.

Figure 10. The temperature dependences of the hydrostatic pressure derivatives of the elastic stiffnesses and the bulk modulus for the dense $\mathrm{YBa}_{2} \mathrm{Cu}_{3} \mathrm{O}_{7-\mathrm{x}}$ ceramic. These pressure derivatives denoted by $\left(\partial C_{L} / \partial P\right)_{P},(\partial \mu \partial P)_{P}$ and $(\partial B / \partial P)_{P}$ correspond to data obtained above the pressure $P_{c}$ at which the change in slope of the pressure dependence of the ultrasonic wave velocity occurs (see figures 3 and 4 ). 


\section{References}

[1] M. Cankurtaran, G.A. Saunders, J.R. Willis, A. Al-Kheffaji and D.P. Almond, Phys. Rev. B 39, 2872 (1989).

[2] A. Al-Kheffaji, M. Cankurtaran, G.A. Saunders, D.P. Almond, E.F. Lambson and R.C.J. Draper, Phil. Mag. B59, 487 (1989).

[3] C. Fanggao, M. Cankurtaran, G.A. Saunders, A. Al-Kheffaji, D.P. Almond, P.J. Ford and D.A. Ladds, Phys. Rev. B. 43, 5526 (1991).

[4] M. Cankurtaran, G.A. Saunders, D.P. Almond, A. Al-Kheffaji, E.F. Lambson and R.C.J. Draper, J. Phys.: Condens. Matter 1, 9067 (1989).

[5] M. Cankurtaran, A. Al-Kheffaji, G.A. Saunders, D.P. Almond and J. Freestone, Supercond. Sci. Technol. 3, 76 (1990).

[6] C. Fanggao, M. Cankurtaran, G.A. Saunders, A. Al-Kheffaji, D.P. Almond and P.J. Ford, Supercond. Sci. Technol. 4, 13 (1991).

[7] W.H. Fietz, M.R. Dietrich and J. Ecke, Z. Phys. B 69, 17 (1987).

[8] J. Ecke, W.H. Fietz, M.R. Dietrich, C.A. Wassilew, H. Wühl and R. Flükiger, Physica C 153-155, 954 (1988).

[9] R.J. Wijngaarden and R. Griessen, Studies of High Temperature Superconductors, ed. A. Narlikar (Nova Science, New York) Vol. 2, p.29 (1989).

[10] J.S. Olsen, S. Steenstrup, I. Johannsen and L. Gerward, Z. Phys. B 72, 165 (1988).

[11] J.S. Olsen, S. Steenstrup, L. Gerward, and B. Sundqvist, Physica Scripta, 44, 211 (1991).

[12] I.V. Medvedeva, Yu.S. Bersenev, B.A. Gizhevsky, N.M. Chebotaev, S.V. Naumov and G.B. Demishev, Z. Phys. B, 81, 311 (1990). 
[13] W.H. Fietz, H.A. Ludwig, B.P. Wagner, K. Grube, R. Benischke and H. Wühl, Proc. of NATO ARW on "Frontiers of High Pressure Research", Colorado State Univ. July 15-18 (1991).

[14] J.D. Jorgensen, S. Pei, P. Lightfoot, D.G. Hinks, B.W. Veal, B. Dabrowski, A.P. Paulikas, R. Kleb and I.D. Brown, Physica C 171, 93 (1990).

[15] S. Pei, J.D. Jorgensen, D.G. Hinks, B. Dabrowski, P. Lightfoot and D.R. Richards, Physica C 169, 179 (1990).

[16] F. Izumi, J.D. Jorgensen, P. Lightfoot, S. Pei, Y. Yamada, E. Takayama-Muromachi and T. Matsumoto, Physica C 172, 166 (1990).

[17] J.B. Walsh, J. Geophys. Res. 70, 381 (1965).

[18] B. Budiansky and R.J. O'Connell, Int. J. Solids Struc. 12, 81 (1976).

[19] R.M. Christensen, Mechanics of Composite Materials, Wiley, New York (1979).

[20] Z. Hashin, J. Mech. Phys. Solids 36, 719 (1988).

[21] U. Balachandran, R.B. Poeppel, J.E. Emerson, S.A. Johnson, M.T. Lanagan, C.A.

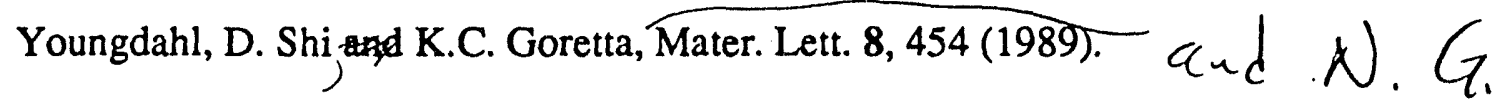

[22] E.P. Papadakis, J. Acoust. Soc. Am. 42, 1045 (1967).

[23] E. Kittinger, Ultrasonics 15, 30 (1977).

[24] R.N. Thurston and K. Brugger, Phys. Rev. 133, A1604 (1964).

[25] C. Ramakrishnan and N. Krishnamurthy, Solid State Commun. 79, 363 (1991).

[26] T.J. Kim, J.Kowalewski, W. Assmus and W. Grill, Z. Phys. B, 78, 207 (1990).

[27] M. Saint-Paul, H. Noel, J.C. Levet, M. Potel and P. Gougeon, Physica C 180, 394 (1991).

[28] S.J. Collocot, G.K. White, S.X. Dou and R.K. Williams, Phys. Rev. B, 36, 5684 (1987).

[29] J.W. Severin and G. De With, Brit. Ceram. Proc. 40, 249 (1988).

[30] T.M. Shaw, S.L. Shinde, D. Dimos, R.F. Cook, P.R. Duncombe and C. Kroll, J. Mater. Res. 4, 248 (1989). 
[31] D.R. Clarke, T.M. Shaw and D. Dimos, J. Am. Ceram. Soc., 72, 1103 (1989).

[32] T.J. Richardson and L.C. De Jonghe, J. Mater. Res. 5, 2066 (1990).

[33] S.C. Lakkad, J. Appl. Phys. 42, 4277 (1971).

[34] J. Toulouse, X.M. Wang and D.J.L. Hong, Phys. Rev. B, 38, 7077 (1988); J. Toulouse, X.Q. Wang and D.J.L. Hong, Phase Transitions, 23, 35 (1990).

[35] D.P. Almond, E.F. Lambson, G.A. Saunders and Wang Hong, J. Phys. F 17, L221 (1987).

[36] H. Kamioka N. Okuda, S. Nitta, Jpn. J. Appl. Phys., 30, 1204 (1991).

[37] D.P. Almond, Q. Wang, J. Freestone, E.F. Lambson, B.C. Chapman and G.A. Saunders, J. Phys.: Condens. Matter 1, 6853 (1989).

[38] M. Cankurtaran, G.A. Saunders, D.P. Almond, A. Al-Kheffaji, J. Freestone, Q. Wang and E.F. Lambson, Physics and Materials Science of .ligh Temperature Superconductors edited by R. Kossowsky, S. Methfessel and D. Wohlleben (Kluwer Academic, Dordrecht) p.627 (1990).

[39] T. Fukami, Ahmed A.A. Yousef, Y. Horie and S. Mase, Physica C 161, 34 (1989).

[40] C. Fanggao, M. Cankurtaran, G.A. Saunders, D.P. Almond, P.J. Ford and A. Al-Kheffaji, Supercond. Sci. Technol. 3, 546 (1990).

[41] S. Hoen, L.C. Bourne, Choon M. Kim and A. Zettl, Phys. Rev. B, 38, 11949 (1988).

[42] S.L. Chaplot, Phys. Rev. B, 42, 2149 (1990).

[43] R.G. Munro, S. Block and G.J. Piermarini, J. Appl. Phys. 56, 2174 (1984).

[44] G.K. White, Studies of High Temperature Superconductors, Vol. 9, ed. A. Narlikar, Nova Science, New York (1991).

[45] R. Ruppin, J. Phys. Chem. Solids 52, 941 (1991).

[46] W.J. Jiang and M.A. Breazeale, Frontiers of Nonlinear Acoustics: Proc. 12th ISNA edited by M.F. Hamilton and D.T. Blackstock, Elsevier Science Publishers Ltd, London (1990). 
[47] D. Mihalovic, K.F. McCarty and D.S. Ginley, to be published in Ferroelectrics (1991).

[48] J. Mustre de Leon, S.D. Conradson, I. Batistic and A.R. Bishop, Phys. Rev. B, 44, 2422 (1991).

[49] K.A. Muller, Z. Phys. B, 80, 193 (1990).

[50] H.J. Bornemann and D.E. Morris, Phys. Rev. B, 44, 5322 (1991). 
Table 1. The ultrasonic wave velocities and elastic moduli of $\mathrm{YBa}_{2} \mathrm{Cu}_{3} \mathrm{O}_{7 . x}$ at $295 \mathrm{~K}$ and atmospheric pressure. The raw experimental data for the ceramic sample (porosity $n=0.042$ ) are given in the first column. Data for the non-porous matrix obtained by applying the wave scattering theory [1] in a porous medium are given in the second coluimn.

\begin{tabular}{|l|l|l|}
\hline & Raw data & Non-porous matrix \\
\hline \hline Ultrasonic wave velocity $(\mathrm{m} / \mathrm{s})$ & & \\
\hline Longitudinal $V_{L}$ & 4283 & 4370 \\
\hline Shear $V_{S}$ & 2717 & 2775 \\
\hline Density $\rho\left(\mathrm{kg} / \mathrm{m}^{3}\right)$ & 6070 & 6338 \\
\hline Longitudinal modulus $C_{L}(\mathrm{GPa})$ & 111.3 & 121 \\
\hline Shear modulus $\mu(\mathrm{GPa})$ & 44.8 & 48.8 \\
\hline Bulk modulus $B_{o}(\mathrm{GPa})$ & 51.6 & 56 \\
\hline Young's modulus $E(\mathrm{GPa})$ & 104 & 113 \\
\hline Poisson ratio $\sigma$ & 0.163 & 0.162 \\
\hline Debye Temperature $\theta_{D}(\mathrm{~K})$ & 370 & 382 \\
\hline \hline
\end{tabular}


Table 2. Comparison between the ultrasonic wave velocities, the elastic stiffness moduli and their hydrostatic pressure derivatives of ceramic samples and very large grained halide-flux-grown material of $\mathrm{YBa}_{2} \mathrm{Cu}_{3} \mathrm{O}_{7-\mathrm{x}}$ at room temperature. These data are not corrected for porosity. Results obtained from a theoretical study [25] are also included.

\begin{tabular}{|c|c|c|c|c|c|}
\hline Description & $\begin{array}{c}\text { Large-grained (halide } \\
\text { flux grown) } \\
{[3]} \\
\end{array}$ & $\begin{array}{c}\text { Ceramic } \\
\text { (course grained) } \\
{[2]} \\
\end{array}$ & $\begin{array}{c}\text { Ceramic } \\
\text { (small grained) } \\
\text { [present study] }\end{array}$ & $\begin{array}{c}\text { Ceramic } \\
\text { (fine grained) } \\
{[1]} \\
\end{array}$ & $\begin{array}{c}\text { Polycrystalline } \\
\text { (calculated data) } \\
{[25]}\end{array}$ \\
\hline Mean grain size & $1-3 \mathrm{~mm}$ & $50 \mu \mathrm{m}$ & $30 \mu \mathrm{m}$ & $10 \mu \mathrm{m}$ & - \\
\hline Density $\left(\mathrm{kg} / \mathrm{m}^{3}\right)$ & 5720 & 5985 & 6070 & 5200 & 6367 \\
\hline $\begin{array}{l}\text { Longitudinal wave velocity } \\
(\mathrm{m} / \mathrm{s})\end{array}$ & 4354 & 4537 & 4283 & 4067 & 4179 \\
\hline Shear wave velocity $(\mathrm{m} / \mathrm{s})$ & - & 2893 & 2717 & 2507 & 2578 \\
\hline $\mathrm{C}_{\mathrm{L}}(\mathrm{GPa})$ & 108 & 123 & 111.3 & 86 & 111.2 \\
\hline$\mu(\mathrm{GPa})$ & - & 50.1 & 44.8 & 32.7 & 42.32 \\
\hline $\mathrm{B}_{0}(\mathrm{GPa})$ & - & 56.4 & 51.6 & 42.4 & 54.78 \\
\hline$\left(\partial C_{L} / \partial P\right)_{P=0}$ & 40 & 145 & 142 & 69 & - \\
\hline$(\partial \mu / \partial P)_{P=0}$ & - & 28 & 40 & 14 & - \\
\hline$(\partial B / \partial P)_{P=0}$ & - & 108 & 88 & 50 & - \\
\hline
\end{tabular}


Table 3. The ultrasonic wave velocities, the elastic stiffnesses and their hydrostatic pressure derivatives of dense, small grained $\mathrm{YBa}_{2} \mathrm{Cu}_{3} \mathrm{O}_{7 \cdot \mathrm{x}}$ at selected temperatures. The pressure derivatives denoted by $\left(\partial C_{L} / \partial P\right)_{P},(\partial \mu / \partial P)_{P}$ and $(\partial B / \partial P)_{P}$ correspond to data obtained above the pressure $P_{c}$ at which the change in the slope of the pressure dependence of the ultrasonic wave velocity occurs (see figures 3 and 4 ).

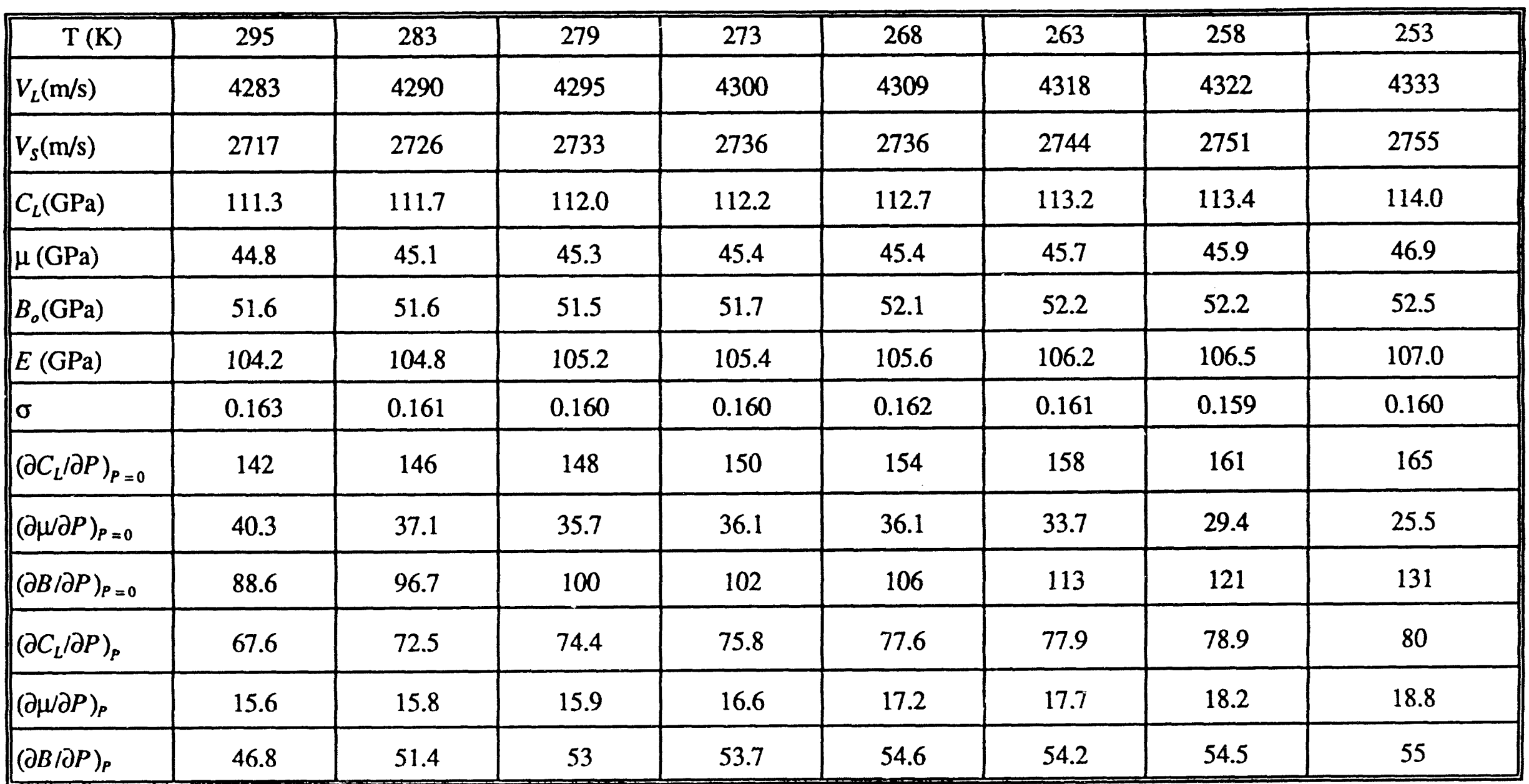




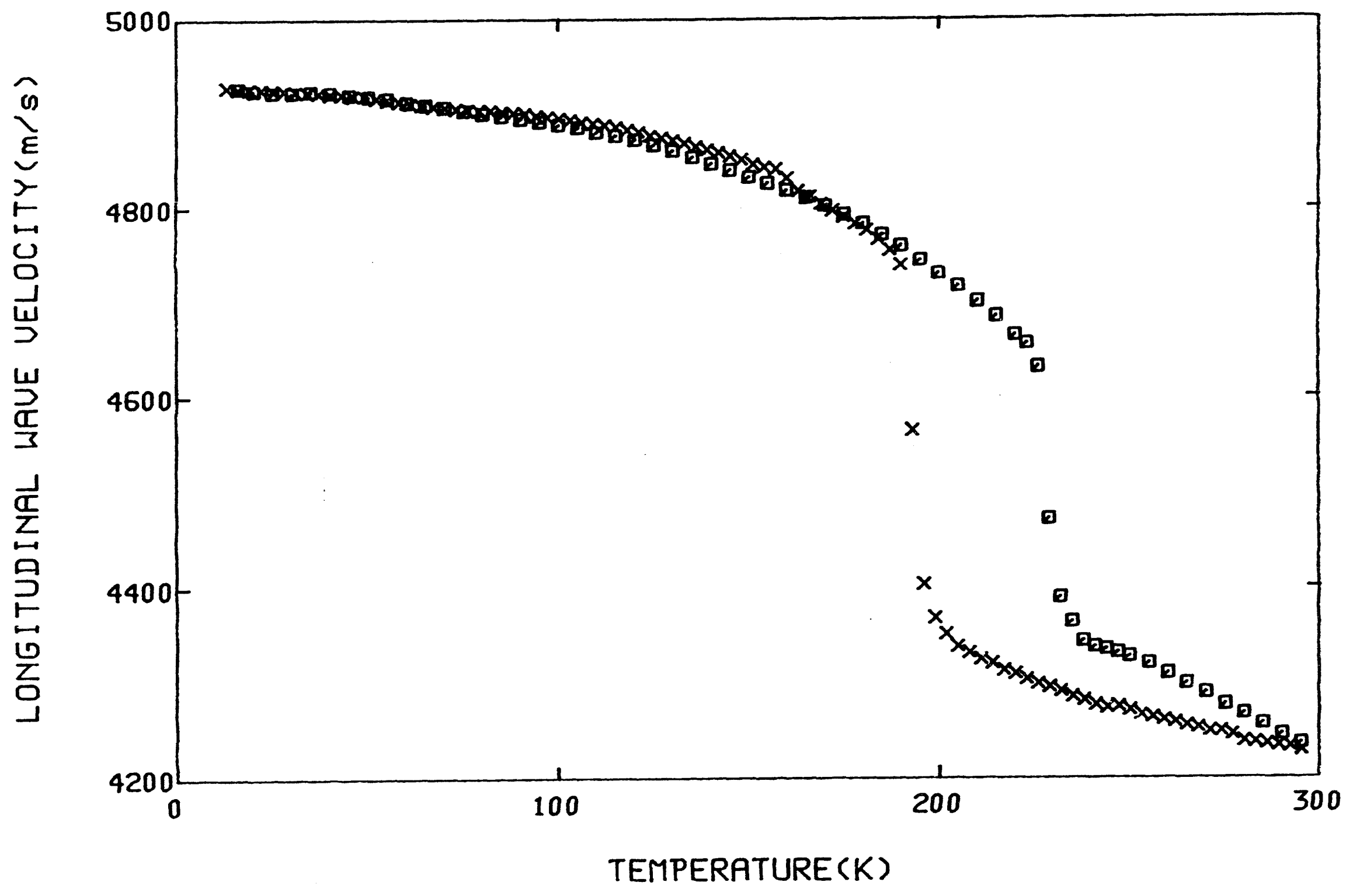

Figure 1. 


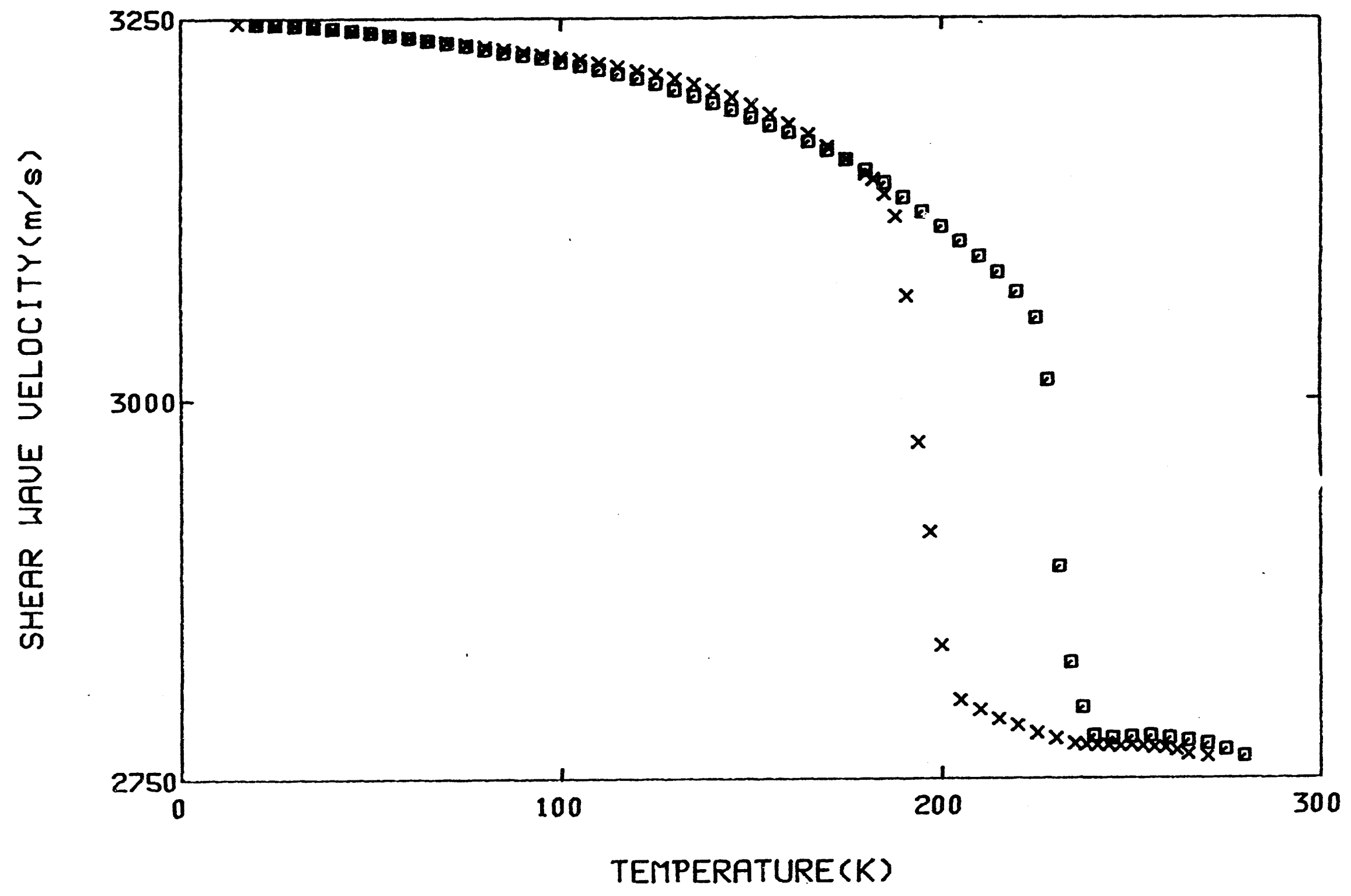

Figure 2. 
LONGITUDINAL WAUE UELOCITY $(\mathrm{m} / \mathrm{s})$

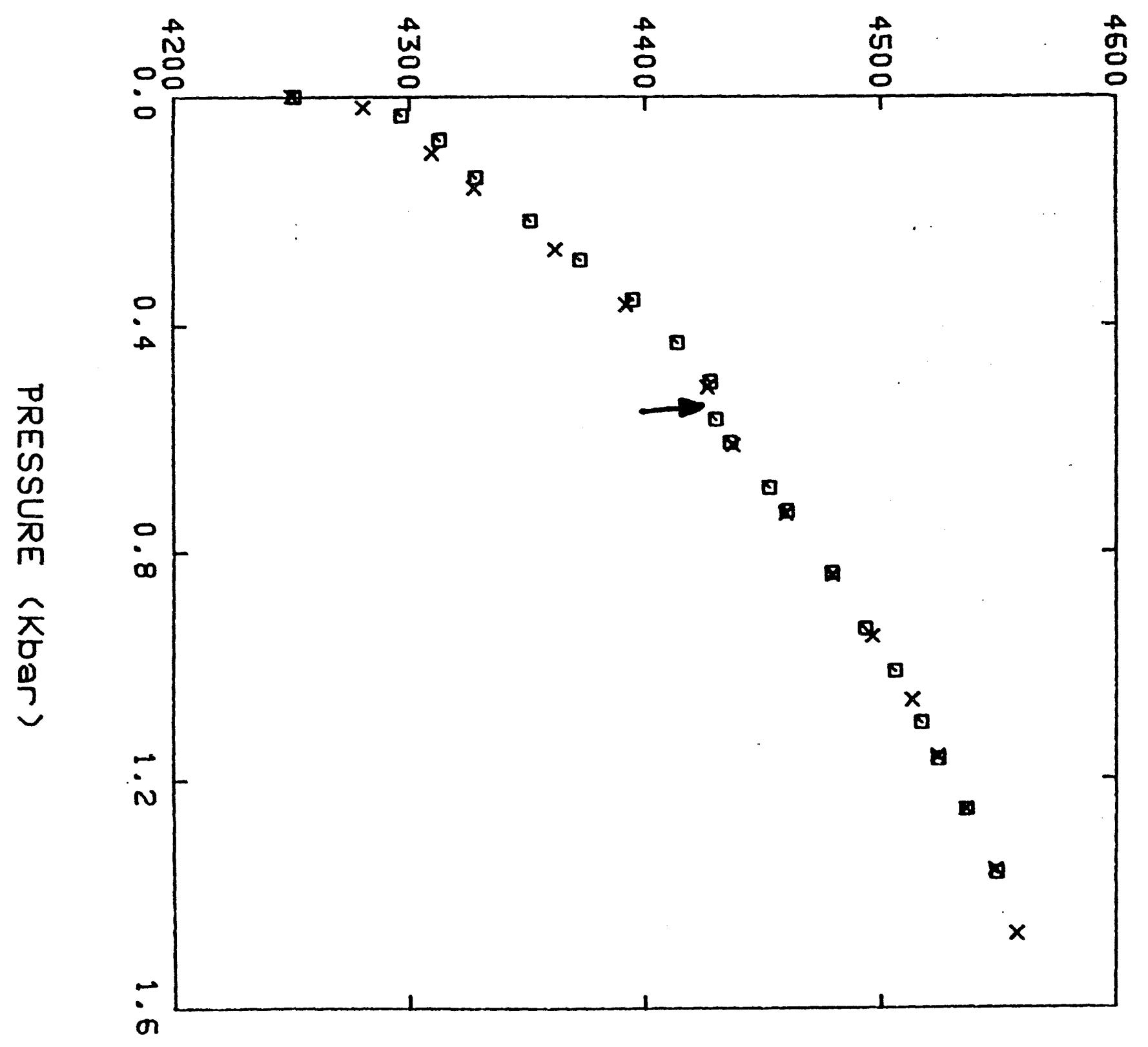




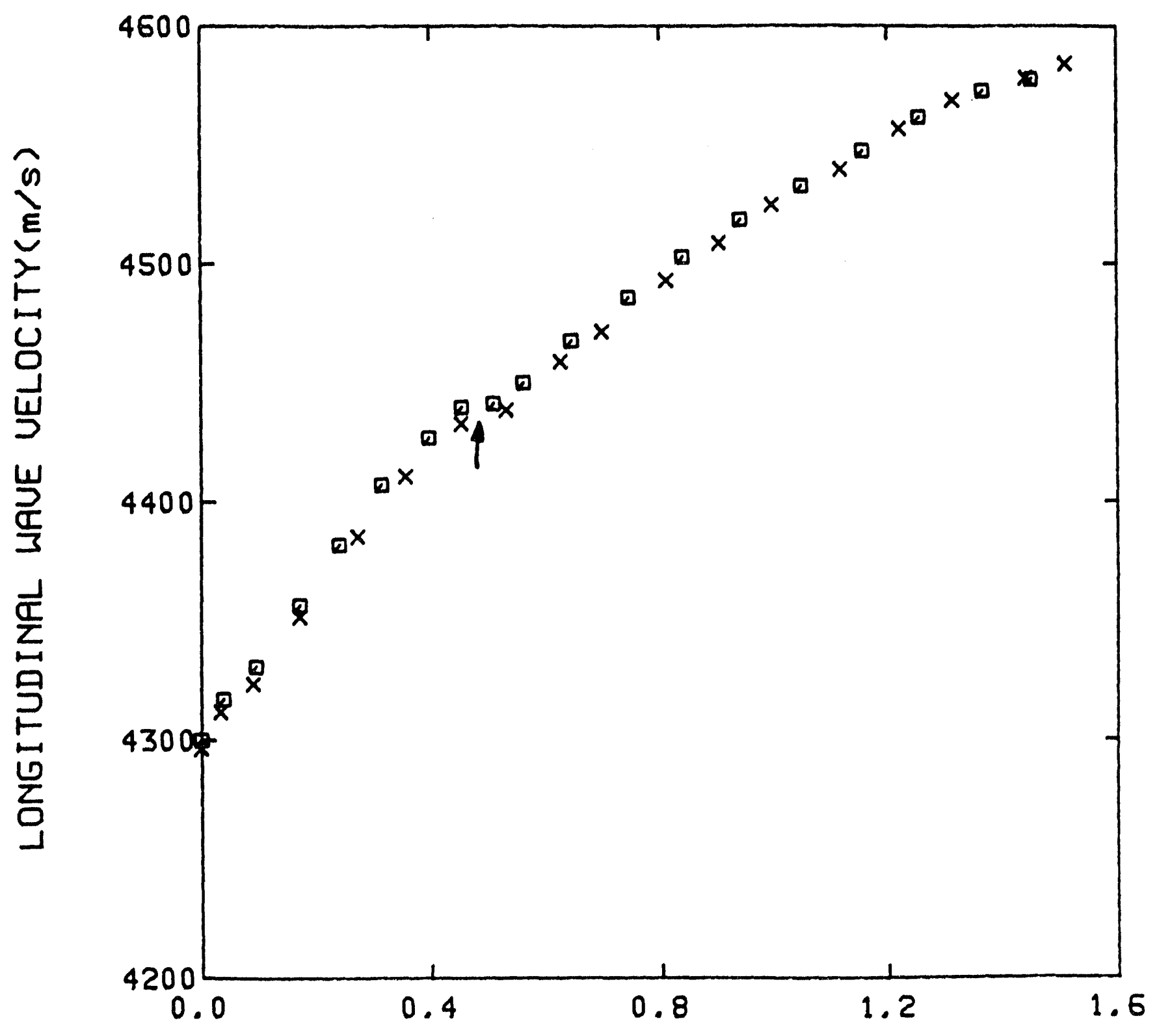

PRESSURE (Kbar) 


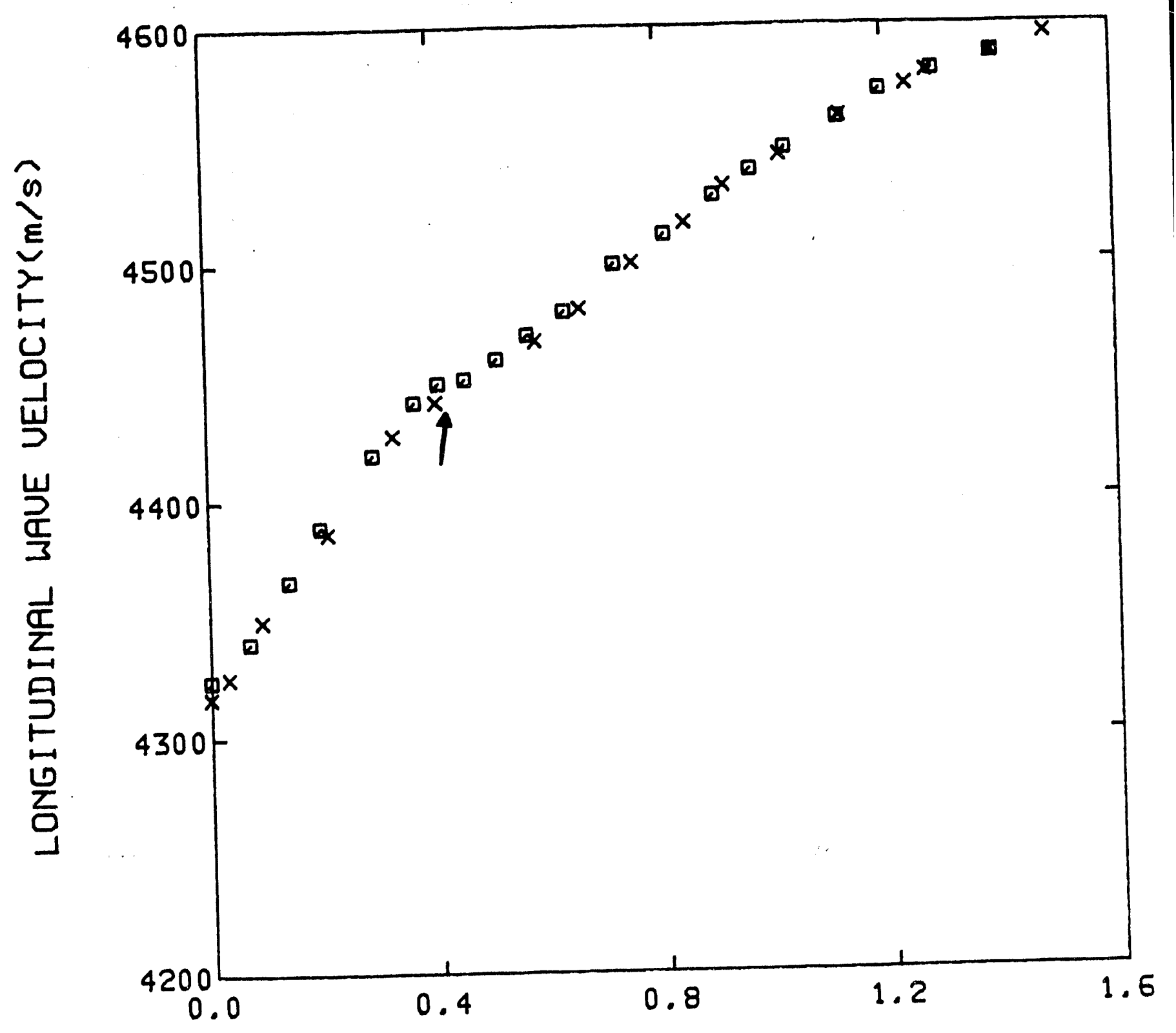

PRESSURE (Kbar) 


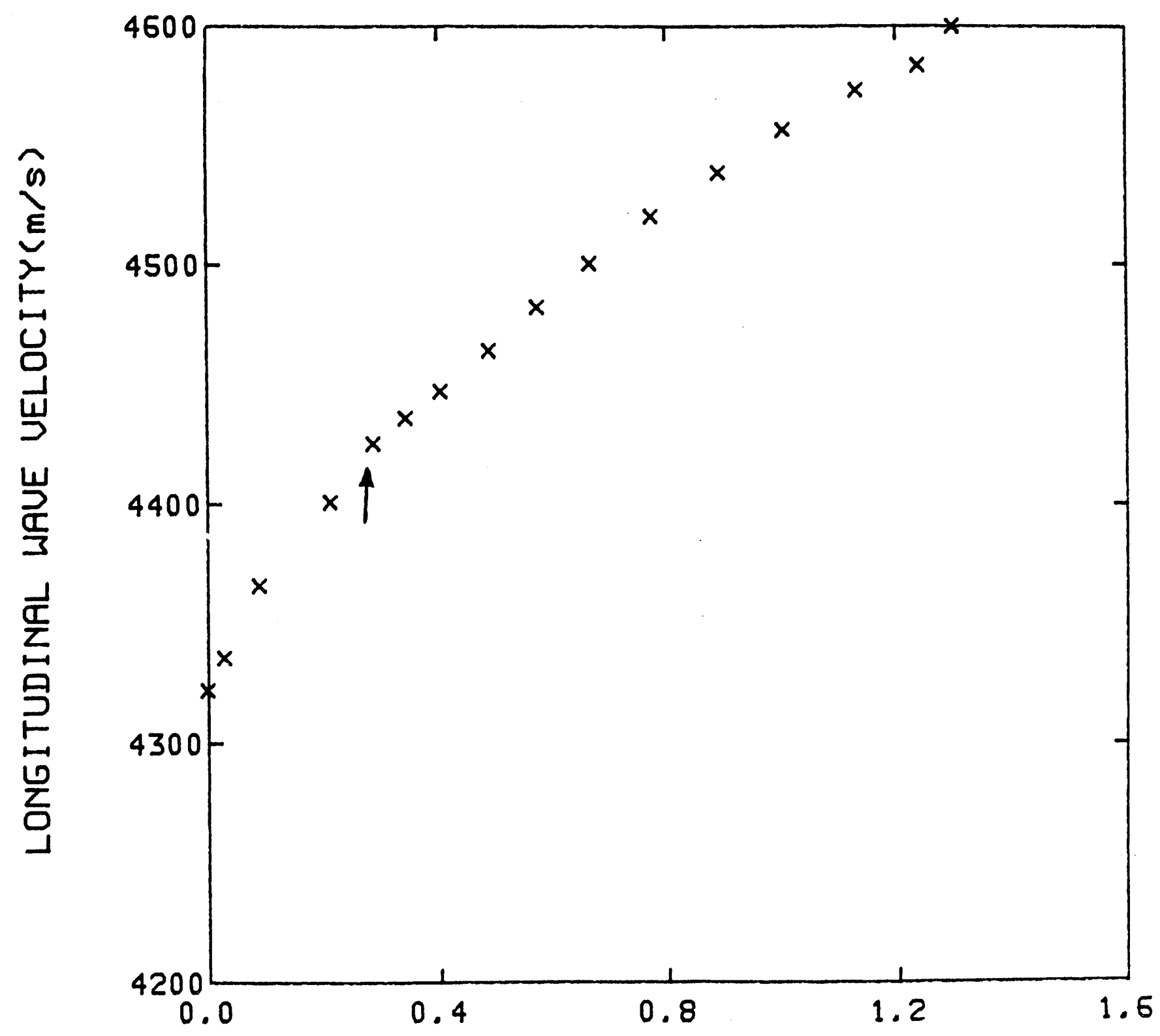

PRESSURE (Kbar)

Figure $3(d)$ 


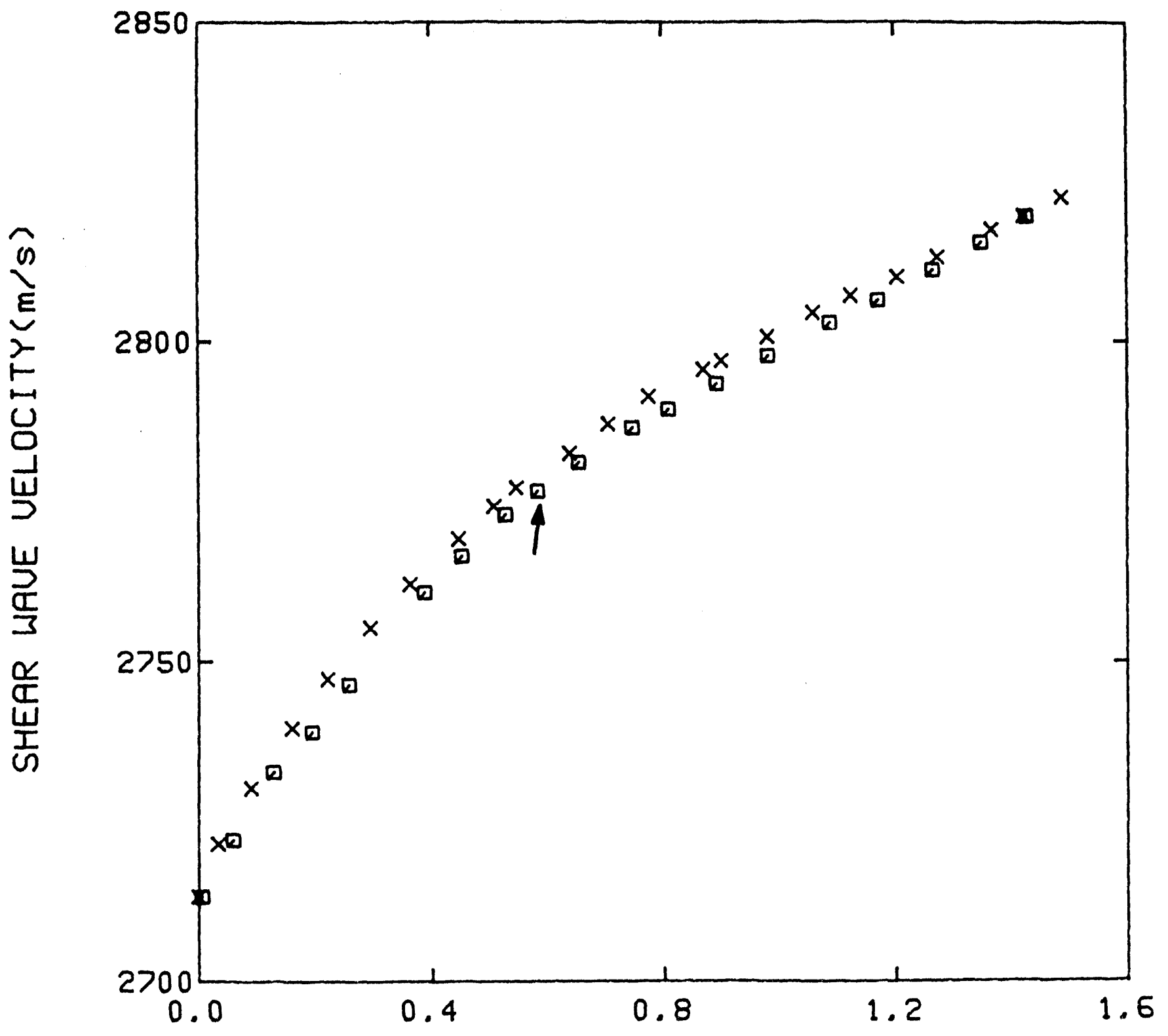

PRESSURE (Kbar)

Figure 4(a) 


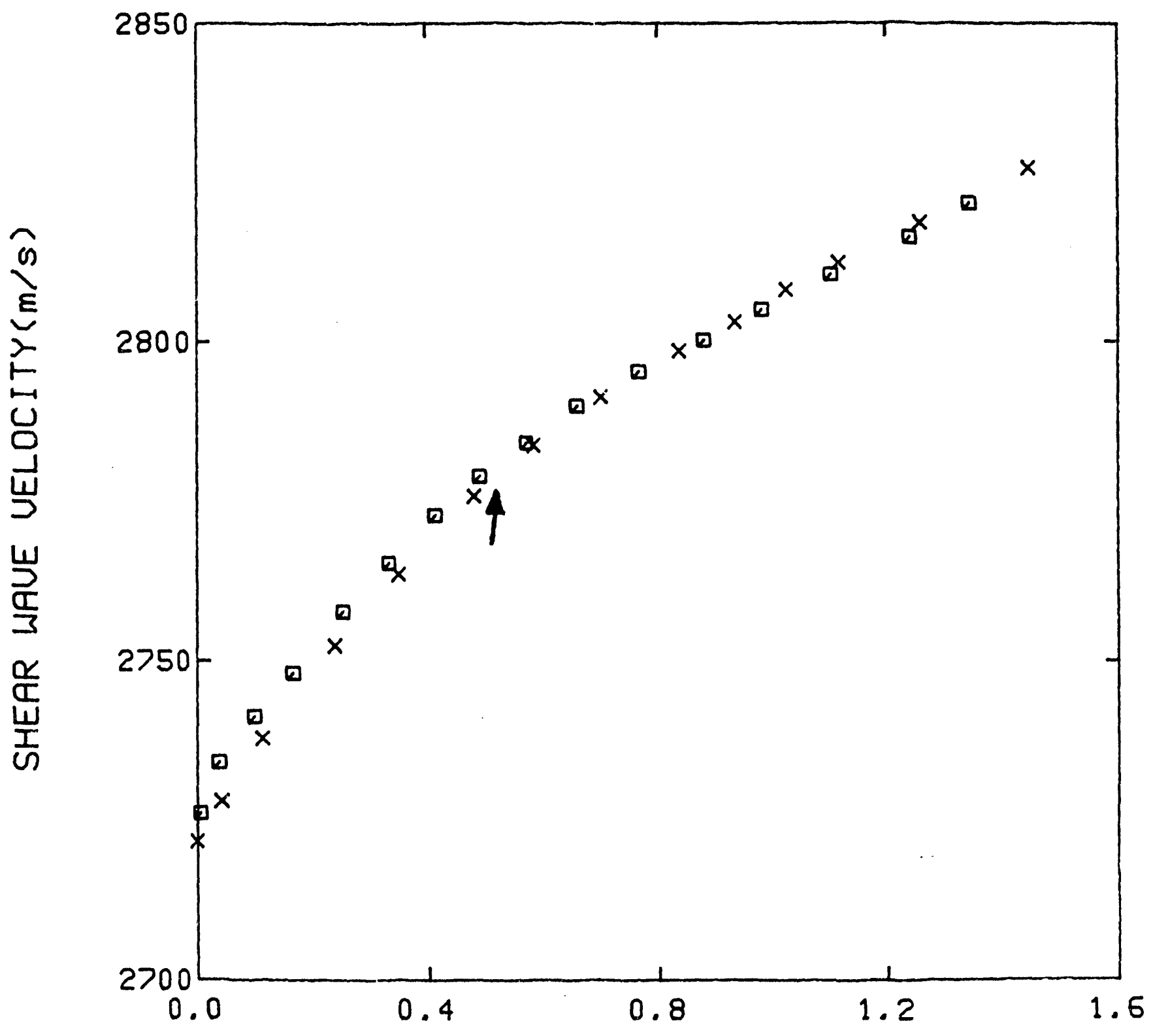

PRESSIJRE (Kbar) 


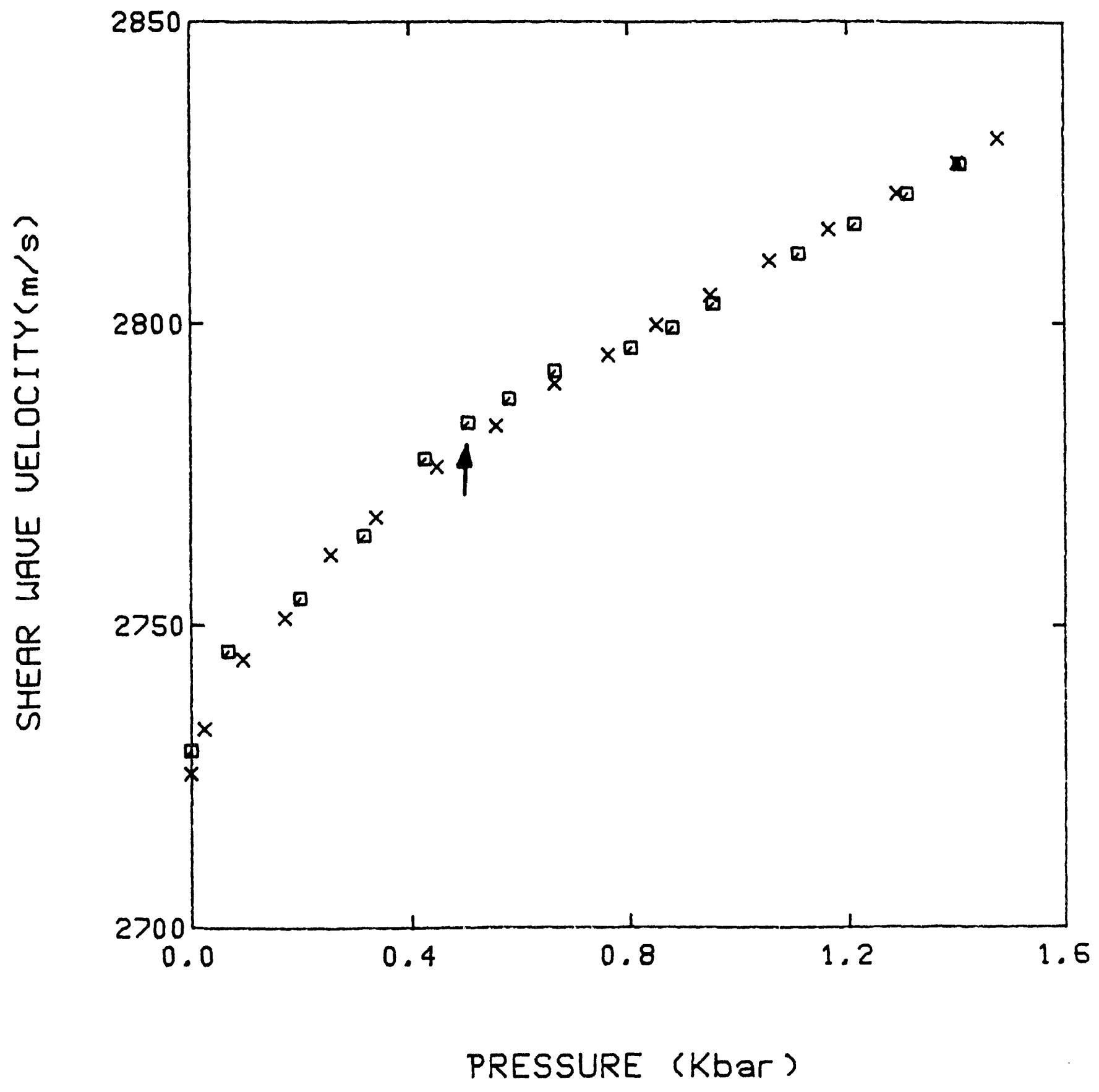

Figure $4(c)$ 


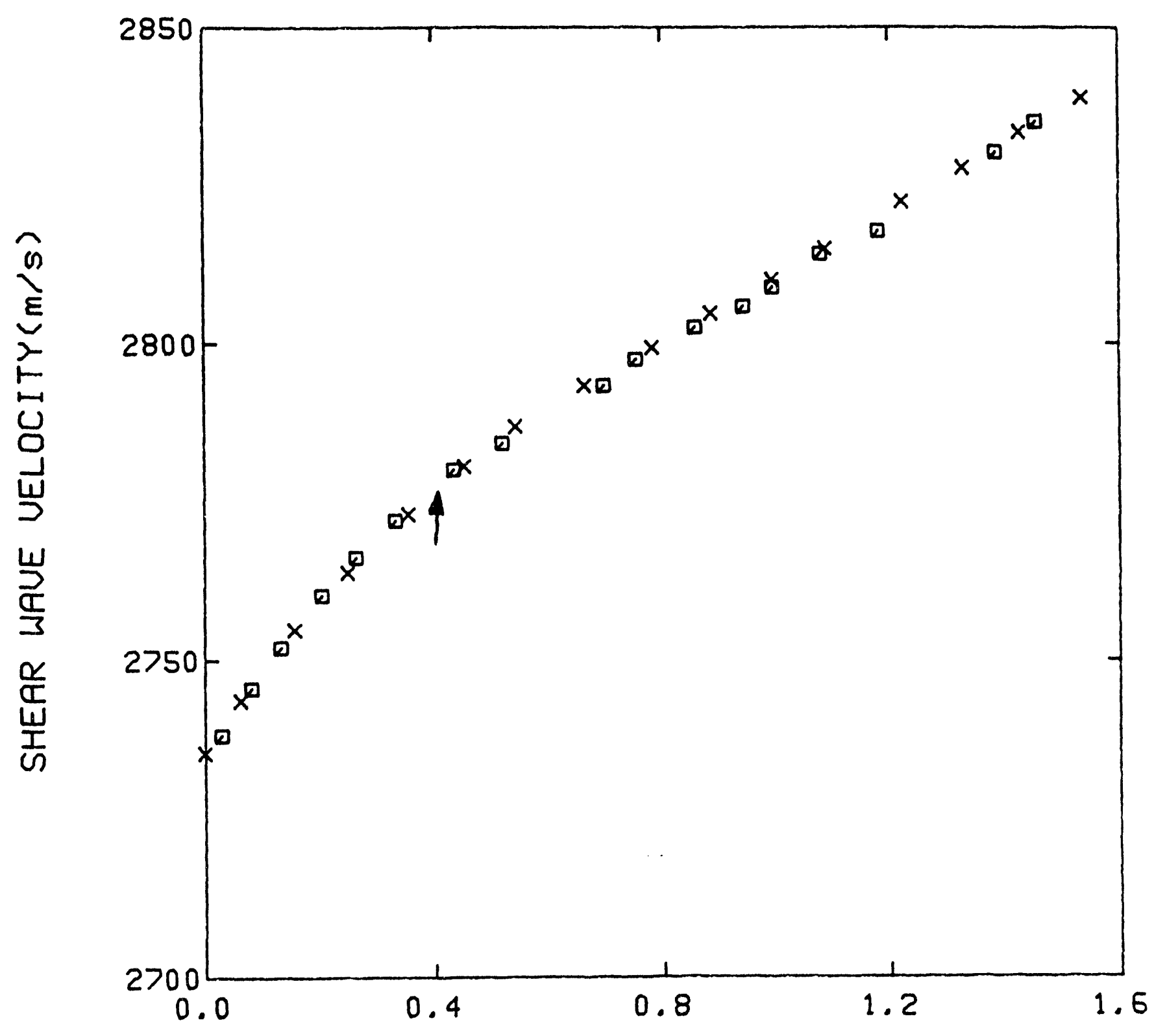

PRESSURE (Kbar)

Figure 4 (d) 


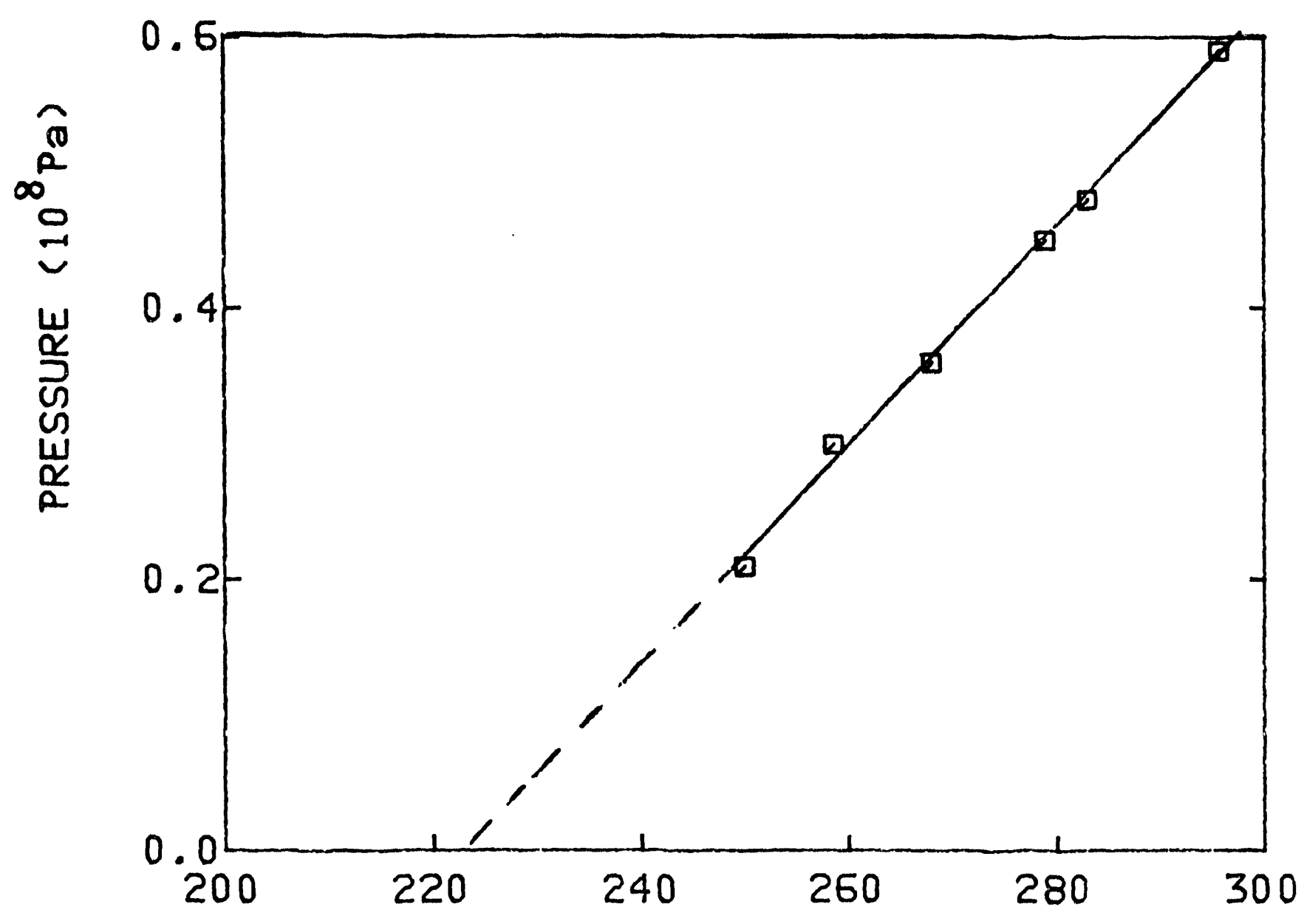

TEMPERATURE ( $K$ )

Figure 5. 


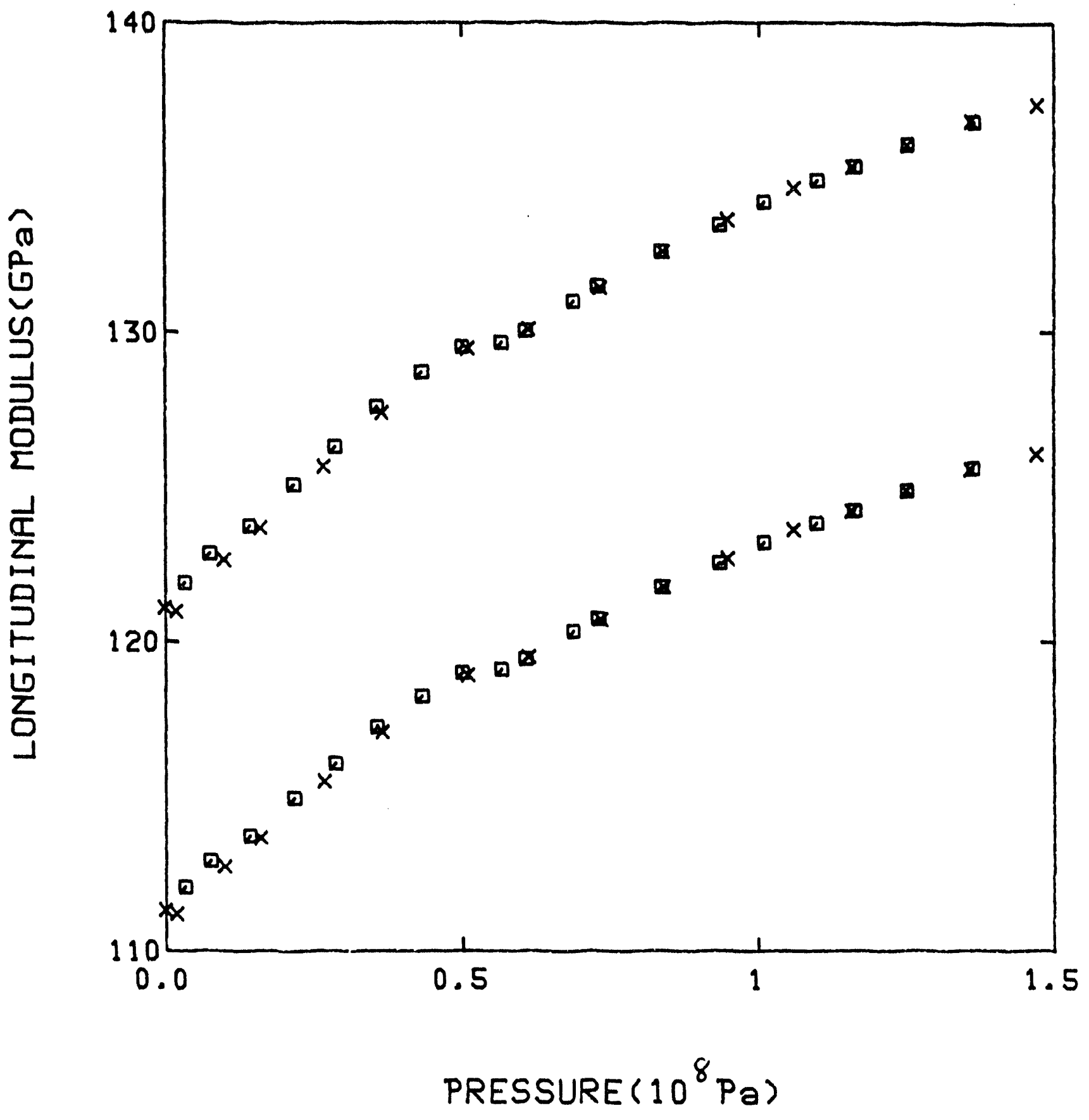

Figure 6. 


\section{SHEAR MODULUS (GPa)}

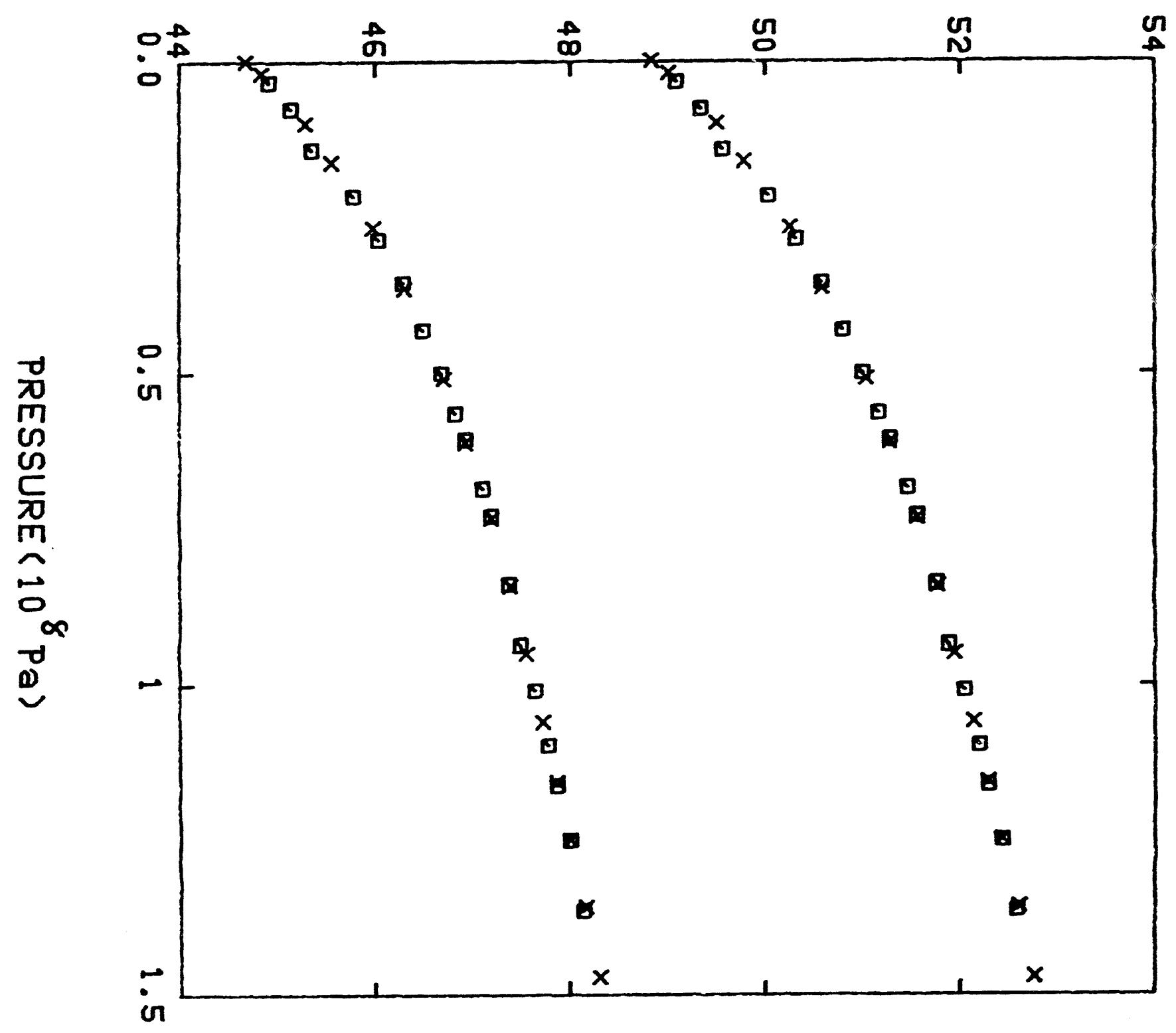




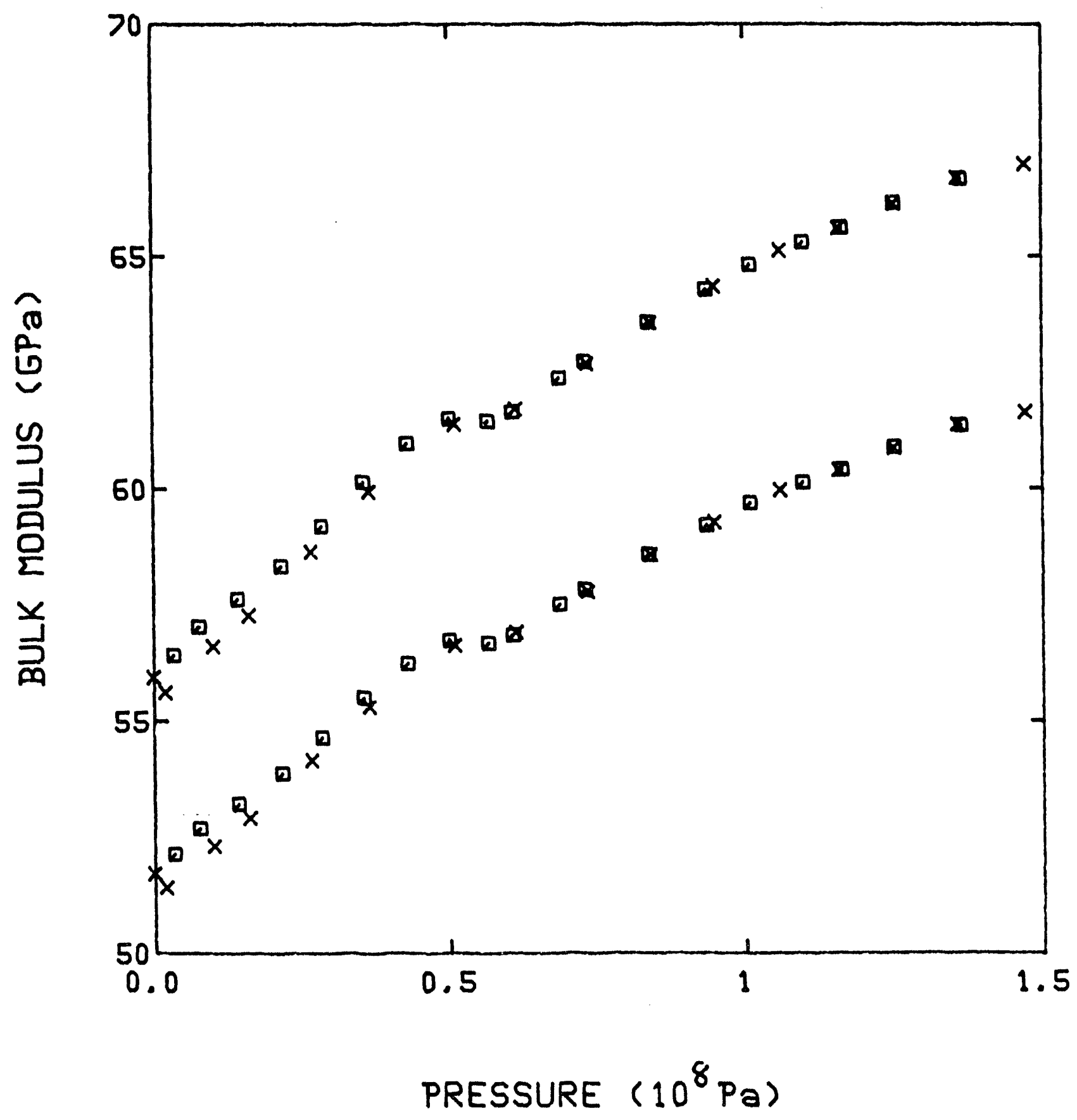

Figure 8. 


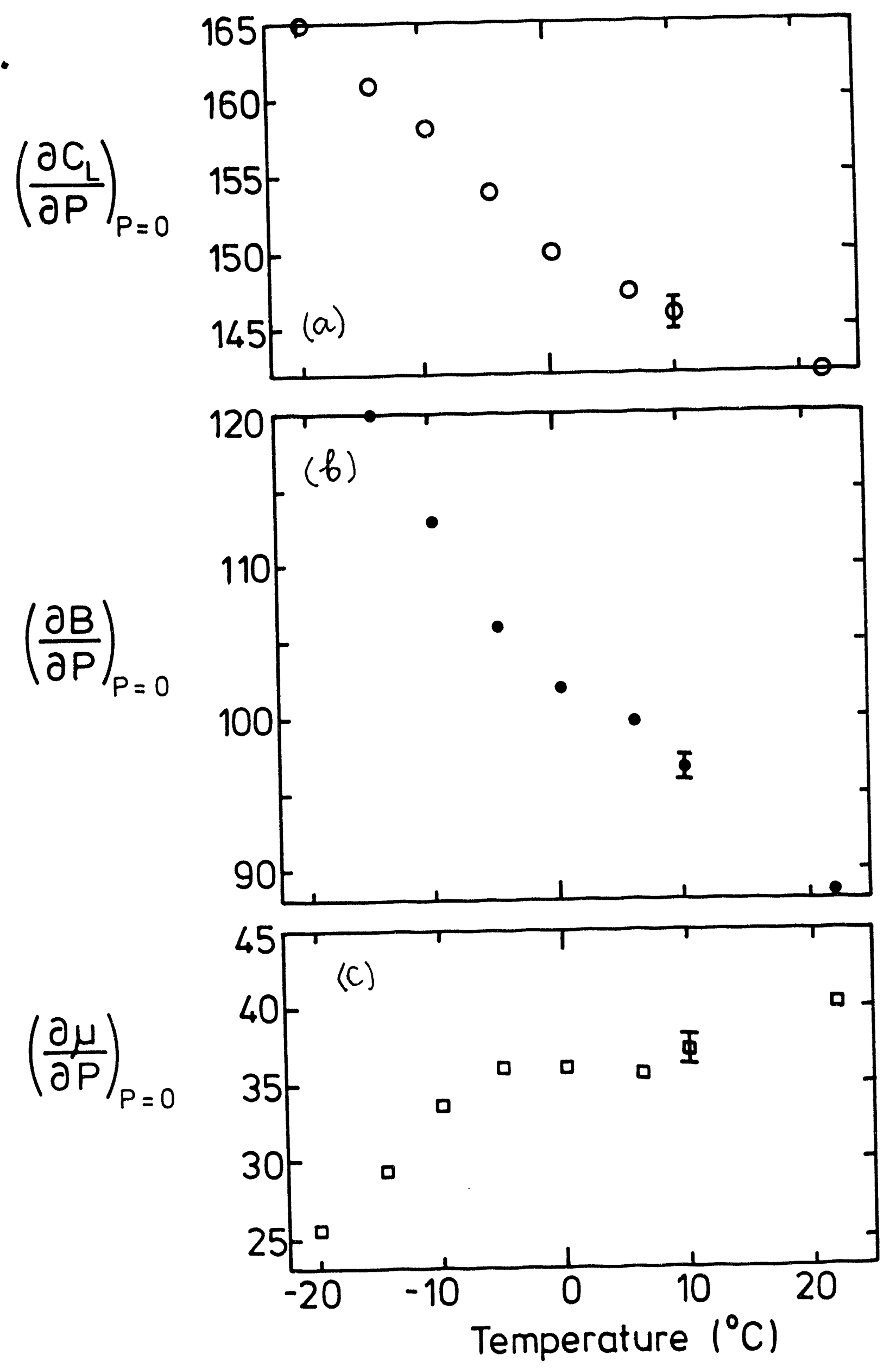

Figure 9. 


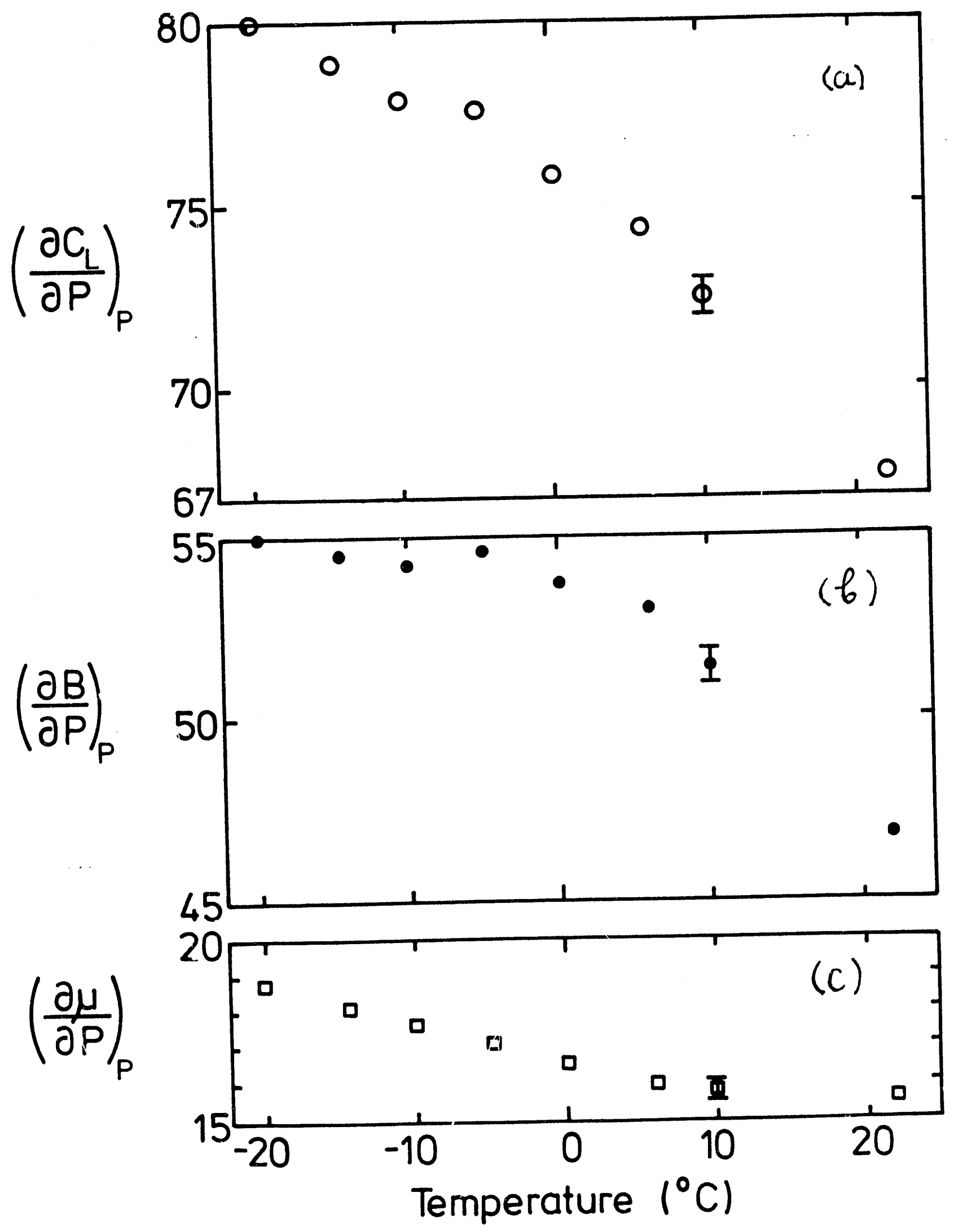

Figure 10. 

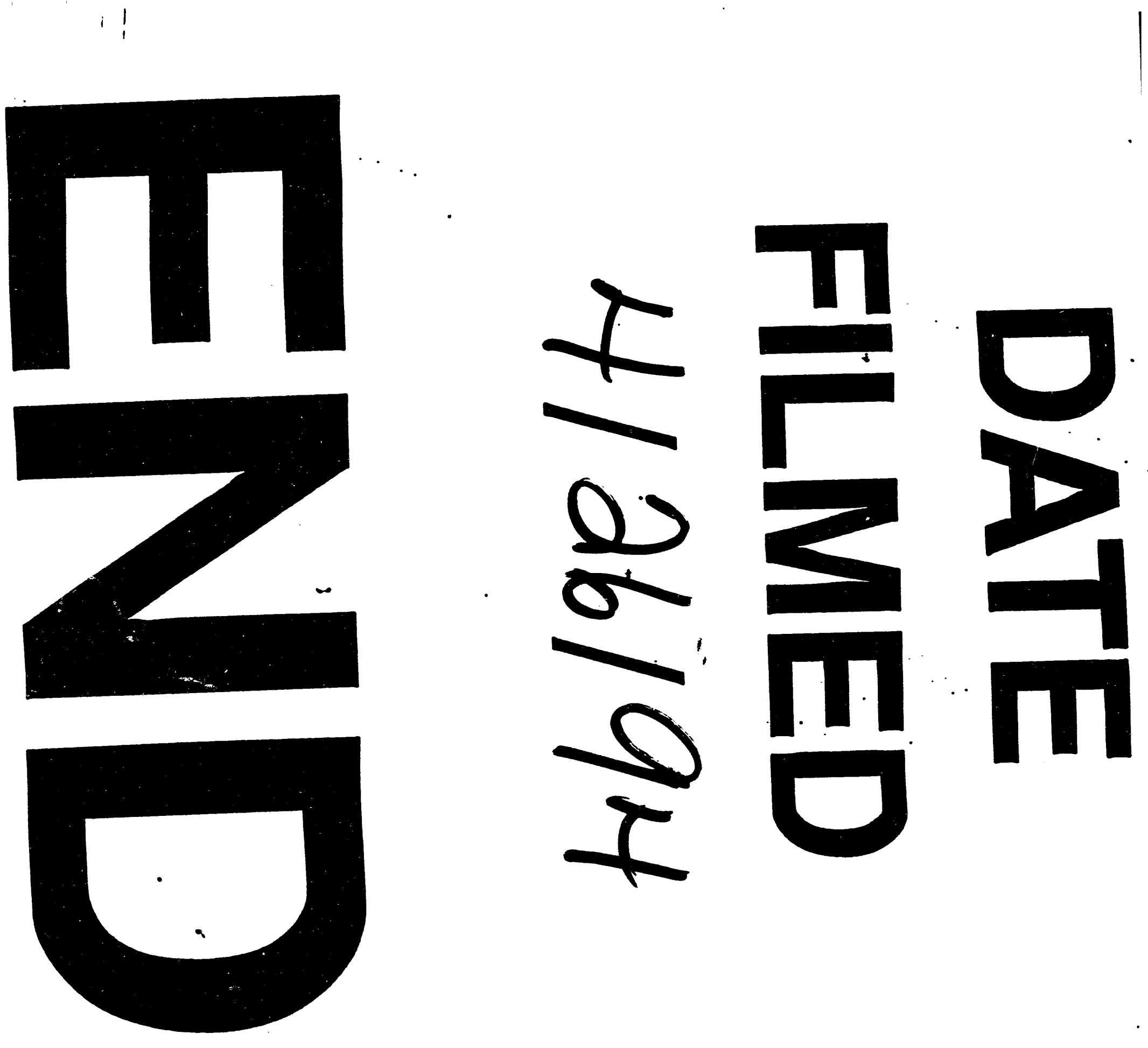
